\title{
Real Incentive Effects of Soft Information
}

\author{
Christensen, Peter Ove; Frimor, Hans; Sabac, Florin
}

Document Version

Accepted author manuscript

Published in:

Contemporary Accounting Research

DOI:

10.1111/1911-3846.12516

Publication date:

2020

Citation for published version (APA):

Christensen, P. O., Frimor, H., \& Sabac, F. (2020). Real Incentive Effects of Soft Information. Contemporary Accounting Research, 37(1), 514-541. https://doi.org/10.1111/1911-3846.12516

Link to publication in CBS Research Portal

\section{General rights}

Copyright and moral rights for the publications made accessible in the public portal are retained by the authors and/or other copyright owners and it is a condition of accessing publications that users recognise and abide by the legal requirements associated with these rights.

Take down policy

If you believe that this document breaches copyright please contact us (research.lib@cbs.dk) providing details, and we will remove access to the work immediately and investigate your claim. 


\section{Real Incentive Effects of Soft Information}

\section{Peter Ove Christensen, Hans Frimor, Florin Sabac}

Journal article (Accepted manuscript*)

\section{Please cite this article as:}

Christensen, P. O., Frimor, H., \& Sabac, F. (2019). Real Incentive Effects of Soft Information. Contemporary

Accounting Research. https://doi.org/10.1111/1911-3846.12516

This is the peer reviewed version of the article, which has been published in final form at DOI: https://doi.org/10.1111/1911-3846.12516

This article may be used for non-commercial purposes in accordance with Wiley Terms and Conditions for Self-Archiving

* This version of the article has been accepted for publication and undergone full peer review but has not been through the copyediting, typesetting, pagination and proofreading process, which may lead to differences between this version and the publisher's final version AKA Version of Record. 


\title{
REAL INCENTIVE EFFECTS OF SOFT INFORMATION*
}

\author{
Peter O. Christensen ${ }^{\dagger}$ \\ Copenhagen Business School \\ Hans Frimor \\ University of Southern Denmark \\ Florin Șabac \\ School of Business, University of Alberta
}

January 30, 2019

\begin{abstract}
Both soft, non-contractible, and hard, contractible, information are informative about managerial ability and future firm performance. If a manager's future compensation depends on expectations of ability or future performance, then the manager has implicit incentives to affect the information. We examine the real incentive effects of soft information in a dynamic agency with limited commitment. When long-term contracts are renegotiated, the rewards for future performance inherent in long-term contracts allow the principal partial control over the implicit incentives. This is because the soft information affects the basis for contract renegotiation. With short-term contracts, the principal has no control over the basis for contract negotiation, thus long-term contracts generally dominate short-term contracts. With long-term contracts, the principal's control over implicit incentives is characterized in terms of effective contracting on an implicit aggregation of the soft information that arises from predicting (forming expectations of) future performance. We provide sufficient conditions for soft information to have no real incentive effects. In general, implicit incentives not controllable by the principal include fixed effects, such as career concerns driven by labour markets external to the agency. When controllable incentives span the fixed effects of career concerns, the latter have no real effects with regard to total managerial incentives - they would optimally be the same with or without career concerns. Our analysis suggests empirical tests for estimating career concerns that should explicitly incorporate non-contractible information.
\end{abstract}

KEYWORDS: dynamic agency, renegotiation, career concerns, non-contractible information.

*Accepted by Raffi Indjejikian. Hans Frimor and Florin Șabac dedicate this paper to the memory of their friend Peter Ove Christensen. We thank Raffi Indjejikian and an anonymous reviewer for their insightful guidance in reviewing this manuscript. We thank Sandra Chamberlain, Robert Göx, Christian Hofmann, Thomas Pfeiffer, and participants at the 2015 Managerial Accounting Section meeting of the AAA, the 2015 Calgary/Temple Conference on Convergence of Financial and Managerial Accounting Research, and seminar participants at LMU Munich and the University of Vienna for comments and helpful discussions. Peter O. Christensen and Hans Frimor gratefully acknowledge financial support from the Danish Center for Accounting and Finance and its sponsors, and Florin Sabac gratefully acknowledges financial support from the Social Sciences and Humanities Research Council of Canada.

${ }^{\dagger}$ Deceased.

†Corresponding author, tel.: + 1780492 8791; e-mail: fsabac@ualberta.ca.

This article has been accepted for publication and undergone full peer review but has not been through the copyediting, typesetting, pagination and proofreading process which may lead to differences between this version and the Version of Record. Please cite this article as doi: $10.1111 / 1911-3846.12516$

This article is protected by copyright. All rights reserved. 


\section{Introduction}

Recent trends in corporate disclosure suggest a proliferation of disclosures of soft (arguably noncontractible) information. A sizeable and growing literature posits that such information has real and/or cosmetic effects on managerial incentives and firm performance. For example, corporate disclosures are criticized for being overly focused on forecasting and the valuation role of accounting to the detriment of the contracting (stewardship) role of accounting information (Glover, Ijiri, Levine, and Liang 2005; American Accounting Association's Financial Accounting Standards Committee 2007). But soft information can implicitly enter managerial incentives (Hayes and Shaefer 2000): for example, but not only, through career concerns (Holmström 1999), contract renegotiation (Hermalin and Katz 1991), or subjective performance evaluation (MacLeod 2003).

The purpose of the present study is to examine the conditions under which soft information has real consequences. In particular, using a contracting framework, the present study illustrates that conventional inferences about the effects of soft information may not be warranted if contractual arrangements between firms and managers can indirectly incorporate soft information. This implies researchers, in order to assess the effects of soft information, must refine their assessment of managerial incentives by distinguishing between "effective incentives" and "nominal incentives."

We model soft information as non-contractible information that can be observed at the interim date in a two-period agency with limited commitment: the principal and the agent either negotiate short-term contracts at the start of each period or can renegotiate a long-term contract at the interim date. In either case, observing the non-contractible information affects contracting (or renegotiation) at the start of the second period and creates implicit incentives.

Implicit incentives are those not explicitly stated as nominal, contractual pay-for-performance. For example, fixed pay negotiated after observing performance information (contractible or not) may in fact be ex ante variable and thus creates implicit incentives; the manager works to improve his or her position in future contract negotiations. From an ex ante perspective, the manager faces effective, or total, incentives that consist of both explicit (nominal) and implicit incentives.

Implicit incentives, in turn, consist of an uncontrollable portion-fixed effects, and those that 
may be controlled by the principal to some extent. In what follows, fixed effects are implicit incentives that the principal cannot control (thus also incentive externalities). For example, career concerns have fixed incentive effects: higher output may lead to higher future compensation when beliefs about managerial ability are revised upward in the labour market; then, the manager has implicit incentives to increase output due to its impact on perceived ability (Fama 1980; Holmström 1999; Gibbons and Murphy 1992). Career concerns arise because the labour market determines the manager's outside options, and those in turn affect the manager's bargaining position and reservation wage. But the principal has no control over these outside options, and thus has no control over the implicit incentives arising from career concerns-those are fixed effects. Incentive ratcheting also has fixed effects: higher performance may lead to lower future compensation when performance targets are revised upward; then, the manager has an implicit incentive to reduce performance due to its impact on future targets (Indjejikian and Nanda 1999; Indjejikian, Matejka, and Schloeser 2014; Indjejikian, Matejka, Merchant, and Van der Stede 2014). Because ratcheting arises from the principal's inability to commit to future contractual terms, these are fixed effects.

The compensation contracts the principal controls may also give rise to implicit incentives, but the principal has some control over those. For example, when renegotiating long-term contracts, the principal may have to offer adjustments to fixed pay at renegotiation time to compensate for renegotiation of future incentives. Fixed pay adjustments depend on realized performance information and thus create implicit incentives for the agent at the initial date. The fixed pay adjustments depend on performance information through the contract to be renegotiated; thus, incentives offered by the principal at the initial date, later to be renegotiated, allow for some degree of control over the agent's implicit incentives.

Implicit incentives may arise from observing both contractible and non-contractible information. The implicit incentives arising from observing contractible information, even if they are fixed effects, can always be compensated for by the principal through adjusting the explicit incentives on that information to achieve the desired total level of incentives. Thus, with only contractible 
information, career concerns have no real consequences in Gibbons and Murphy (1992) because the principal has control and can compensate for the fixed effects-the principal supplements the implicit incentives to increase performance with explicit incentives. ${ }^{1}$ Similarly, if ratcheting is only based on contractible information as in Indjejikian and Nanda (1999), the principal can compensate for the fixed effects and there are no real consequences (Christensen et al. 2003).

The implicit incentives arising from observing non-contractible information cannot always be compensated for by the principal. For example, absent any contractible performance information, and thus any explicit incentives, career concerns have real consequences in Fama (1980) and Holmström (1999) because the principal has no control and total incentives are entirely fixed effects. More generally, the real incentive effects of soft information depend on the principal's ability to compensate for the fixed incentive effects arising from it.

We use a two-period LEN model (linear contracts, exponential agent utility, and normally

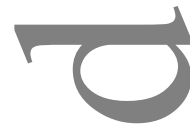
distributed performance measures) to demonstrate that renegotiation of a long-term contract effectively allows contracting on an aggregation of the soft information, and we characterize a minimal effectively contractible aggregation. ${ }^{2}$ As a particular case, we obtain conditions under which all the soft information is effectively contractible through renegotiation, thus eliminating any real conequences of implicit incentives as in Gibbons and Murphy (1992). Finally, we derive conditions under which implicit incentives have no real consequences even when the soft information is not effectively contractible: the effectively contractible aggregation must give the principal sufficient control to compensate for the fixed effects.

In our model, soft information creates implicit incentives by affecting the acceptability of contract offers to the manager at the interim date. ${ }^{3}$ That in turn depends on the contracting environ-

\footnotetext{
${ }^{1}$ Total incentives are the same as in a renegotiated long-term contract in the models of Gibbons and Murphy (1992), Meyer and Vickers (1997), Christensen, Feltham, and Șabac (2003), and Șabac (2008). Career concerns do not add to the constraints on total incentives imposed by lack of commitment.

${ }^{2}$ The career concerns model introduced by Holmström (1999) and widely adopted in the literature relies on normally distributed information with a simple linear separable structure but exogenously specifies career concerns without explicit incentive contracts. Gibbons and Murphy (1992) and Meyer and Vickers (1997) have explicit contracts along with career concerns but within a LEN framework that is consistent with the normally distributed information in Holmström (1999).

${ }^{3}$ Managerial actions are independent of observed past information in the LEN model. This eliminates other potential sources of implicit incentives such as wealth effects.
} 
ment, on performance expectations, and on the manager's alternative options. Renegotiation of a long-term contract is based on the expectation of future payoffs under the initial contract—this "locks-in" at renegotiation time some of the manager's future compensation. But expected future payoffs depend on expected future performance, and thus on an implicit aggregation of the observed information. By offering initial incentive rates on the contractible second-period performance measures that are later renegotiated, the principal controls the basis for renegotiation, and thus incentive weights on the implicit aggregation. This makes the implicit aggregation of non-contractible information effectively contractible.

In contrast, a short-term contract offer at the interim date depends on an implicit aggregation of the observed information, but with fixed incentive weights determined by (second-period) contract terms the principal cannot commit to ex ante. Without explicit incentives for second-period performance offered initially, the principal does not control the basis for renegotiation. Consequently, the implicit aggregation of observed information is not effectively contractible because its incentive effects are fixed by the labour market and the manager's bargaining power. Thus, the implicit incentives arising from soft information under short-term contracts with career concerns or incentive ratcheting are fixed effects that cannot be compensated for.

Renegotiation of long-term contracts and non-contractible information are the main features of the model. With renegotiation of long-term contracts, the implicit managerial incentives arising from non-contractible information consist of fixed effects due to career concerns or incentive ratcheting and controllable incentives due to renegotiation of long-term contracts. With short-term contracts, the implicit managerial incentives arising from non-contractible information consist entirely of fixed effects. Consequently, long-term contracts dominate short-term contracts by allowing the principal some control over the implicit incentives based on non-contractible information. In contrast, when all performance information is contractible, short-term contracts with interim participation constraints are equivalent to renegotiating a long-term contract.

We contribute to the literature on contract renegotiation and career concerns as follows. First, we characterize an implicit aggregation of the non-contractible information that is effectively con- 
tractible through renegotiation of long-term contracts. This extends Hermalin and Katz (1991) to include multiple signals and partial contracting on the non-contractible information.

Second, we show that implicit incentives have no real consequences if, and only if, the effectively contractible aggregate of the non-contractible information is an incentive sufficient aggregate (observing it can be substituted for the non-contractible information without affecting the agency). This requires less than explicit contractibility of all information as assumed by Gibbons and Murphy (1992), or effective contractibility of non-contractible information, as obtained in Hermalin and Katz (1991), but with the same effect of neutralizing (spanning) fixed implicit incentives.

Third, our analysis suggests empirical tests to estimate the real consequences of implicit incentives should explicitly incorporate non-contractible information. The suggested approach relies on separately estimating the implicitly contractible aggregate of non-contractible information; the remaining sensitivity of compensation (if any) to non-contractible information captures the real consequences of implicit incentives.

Finally, we contribute to the career concerns literature by including career concerns in the renegotiation design for long-term contracts (Aghion, Dewatripont, and Rey 1994). Career concerns affect the starting point in renegotiation such that, if all information is contractible, there is nd difference between short-term contracts and long-term contracts with renegotiation. However, if there is non-contractible information, long-term contracts with renegotiation give the principal more control over implicit incentives, and thus dominate short-term contracts. ${ }^{4}$ In particular, we provide necessary conditions for the robustness of results on career concerns to the introduction of long term contracts: the non-contractible information should be informative about managerial ability beyond what is already embedded in forecasts of future (contractible) managerial performance. Otherwise, career concerns have no real effects, and thus results driven by the inefficiencies of career concerns incentives no longer hold.

\footnotetext{
${ }^{4}$ Long-term contracts and renegotiation design to allow for career concerns require some limited commitment from the principal and the agent. We do not consider full commitment to long-term contracts because they would not be affected by either non-contractible information or career concerns. With non-contractible information, full commitment dominates renegotiation of long-term contracts only when the inefficiencies of renegotiation dominate the incremental gain from implicitly contracting on the unverifiable information.
} 
Our findings imply that the balance between soft and hard performance information is important for stewardship purposes. Expanding the disclosure of soft information without that of hard information will make implicit incentives arising from the former harder to control because the effectively contractible aggregation of soft information is constrained by the available hard information. A higher number of soft measures leads to more aggregation without necessarily expanding the principal's scope of control.

\section{Related literature}

Uncertainty concerning managerial ability has been shown to affect pay for performance sensitivity in both adverse selection and career concerns settings. For example, when managers have private information about their own ability, output is used to provide incentives and to screen managers for ability, as in Arya and Mittendorf (2005) or Dutta (2008). In contrast, a career concerns setting is characterized by symmetric uncertainty about managerial ability - both the manager and the labour market learn about managerial ability from observing output. Dewatripont, Jewitt, and Tirole (1999) rank information systems, and Arya and Mittendorf (2011) consider the desirability

of aggregated versus disaggregated performance information when incentives can only be provided through career concerns.

Explicit contractual incentives not only add to implicit incentives and complete the total managerial incentives, but also generate controllable implicit incentives through contract renegotiation. The principal thus gains an additional set of (effectively) contractible performance measures that are valuable because they allow fine-tuning total risk premia in incentive contracts and improving the congruity of performance measurement in multi-task settings (Feltham and Xie 1994).

The implicitly contractible aggregation of non-contractible information arises from forecasting future contractible performance measures. Thus, its effective contractibility through contract renegotiation relies on the confirmatory role of (backward-looking) contractible information. This provides another instance where accounting-based performance measures play a confirmatory role, 
a point emphasized previously in agency models with disclosure of (non-contractible) private managerial information (Dye 1983; Stocken 2000; Gigler and Hemmer 2001; Șabac and Tian 2015).

When all information is contractible, career concerns have no real consequences for managerial actions or the principal's surplus_career concerns only affect how total incentives are split between implicit and explicit incentives. In Gibbons and Murphy (1992) ability is transferable and constant; as a consequence implicit incentives are strong early in an agent's career but weaken over time-to compensate, explicit incentives are strengthened as the agent's career matures. Consequently, given explicit incentive contracts, career concerns can have real consequences for total incentives and managerial actions only when based on non-contractible information.

Kaarbøe and Olsen $(2006,2008)$ and Autrey, Dikolli, and Newman (2007, 2010) address the efficiency of alternative information structures combining contractible and non-contractible information when career concerns are present. When all information is contractible, the restriction to short-term contracts subject to interim participation constraints commonly used in career concerns models is innocuous because there is no value to long-term contracting. But in the presence of non-contractible information, the restriction to short-term contracts-employed in the studies above combining contractible and non-contractible information-is no longer innocuous because the renegotiation driving career concerns can also drive implicit contracting on unverifiable information if contracts are long-term. The inefficiencies arising from career concerns are robust to the introduction of long-term contracts only if the non-contractible information is informative about managerial ability beyond what is already embedded in forecasts of future (contractible) managerial performance. Otherwise, career concerns have no real consequences.

\section{Principal-agent model with non-contractible information}

We use a two-period version of the single-period multi-task LEN model of Holmström and Milgrom (1991) and Feltham and Xie (1994). A risk neutral principal owns a production technology that requires productive effort on $m$ tasks $a_{t}=\left(a_{t 1}, a_{t 2}, \ldots, a_{t m}\right) \in \mathbb{R}^{m}$ from a risk and effort 
averse agent in each of the two periods $t=1,2 .^{5}$ The agent has exponential utility of terminal wealth with multiplicatively separable effort cost $u\left(w, a_{1}, a_{2}\right)=-\exp \left(-r\left(w-\kappa\left(a_{1}\right)-\kappa\left(a_{2}\right)\right)\right)$, where $w$ is the agent's terminal wealth, $\kappa\left(a_{t}\right)$ is a strictly convex function of the agent's action representing the agent's personal effort cost in period $t$, and $r$ is the agent's risk aversion. ${ }^{6}$

The single-dimensional output for a given level of agent effort $a_{t}$ is $\Pi_{t}=b_{t}\left(a_{t}\right)+\zeta_{t}, t=1,2$, where $\zeta=\left(\zeta_{1}, \zeta_{2}\right)$ is a vector of zero-mean joint normally distributed noise terms independent of the agent's actions $a_{t}$, and the principal's expected benefit $b_{t}\left(a_{t}\right)$ is a weakly concave function of the agent's actions in each period. The actions $a_{t}$ are unobservable and, hence, non-contractible.

A vector $y_{t}$ of $n$ contractible performance measures is reported in each period, i.e., $y_{t}=$ $\left(y_{t 1}, y_{t 2}, \ldots, y_{t n}\right), t=1,2$. The performance measures are joint normally distributed with $y_{t}=$ $M_{t} a_{t}+\varepsilon_{t}$, where $\varepsilon_{t} \sim N\left(0, \Sigma_{\varepsilon t}\right)$. Here, $M_{t}$ is an $n \times m$ matrix of sensitivities of the $n$ performance measures to managerial effort on the $m$ tasks, and $\Sigma_{\varepsilon t}$ is the $n \times n$ variance-covariance matrix of the noise terms. The vectors of noise terms $\varepsilon_{t}$ have mean zero, and their distribution is independent of $a_{t}$. The output $\Pi_{t}$ may or may not be observable and contractible; if it is observed, it is contractible and assumed to be part of the performance measure $y_{t}$.

A set of $k$ non-contractible signals $z=M a_{1}+\delta$ is observed at the same time as $y_{1}$. Here, $M$ id the $k \times m$ matrix of sensitivities of the $k$ non-contractible signals to managerial effort on the $m$ tasks in the first period. The distribution of $\delta$ is independent of $a_{t}$, and $\delta \sim N\left(0, \Sigma_{\delta}\right)$. The noise terms $\varepsilon_{t}$ and $\delta$ may be correlated with each other, or with the output noise $\zeta_{t}$.

We assume there is an unobservable and persistent agency characteristic $\theta \sim N\left(0, \sigma_{\theta}\right)$, which we term "managerial ability," that influences managerial compensation, and thus incentives. At the outset, the principal and the agent are symmetrically uninformed about $\theta$. The contractible

${ }^{5}$ In what follows, we use the following vector and matrix algebra notation. Vectors are thought of as column vectors in all cases, and the scalar product of two vectors $a$ and $b$ in $\mathbb{R}^{m}$ is denoted by $a \cdot b$. For a matrix $M=$ $\left[m_{i j}\right]_{1 \leq i \leq n, 1 \leq j \leq m}$ with $n$ rows and $m$ columns, we do not distinguish between the matrix and the associated linear operator $M: \mathbb{R}^{m} \longrightarrow \mathbb{R}^{n}$ defined by $M b=\left(\sum_{1 \leq j \leq m} m_{i j} b_{j}\right)_{1 \leq i \leq n}$. We denote the transpose matrix as $M^{*}$, the same as the adjoint operator. Throughout the paper we use $A^{*} a \cdot b=a \cdot A b$ and $(A B)^{*}=B^{*} A^{*}$.

${ }^{6}$ We assume a single consumption date and no discounting for simplicity. Our results carry over with minor modifications to a model with time-additive utility, multiple consumption dates, and discounting, while their qualitative nature remains unchanged; for details, see Dutta and Reichelstein (1999), Christensen, Feltham, Hofmann, and Șabac (2003), and Șabac (2007, 2008).

This article is protected by copyright. All rights reserved. 
performance measures $y_{t}$ and the non-contractible signals $z$ may be correlated with and, thus, be informative about $\theta$.

We only assume the performance measures $y_{t}$, managerial ability $\theta$, and the non-contractible information $z$ are joint normally distributed with conditional expectations at date $t=1$ given by

$$
\begin{aligned}
\mathrm{E}_{1}\left[y_{2} \mid \hat{a}_{1}, \hat{a}_{2}\right] & =\alpha_{1}\left(\hat{a}_{1}, \hat{a}_{2}\right)+\Lambda y_{1}+\Gamma z, \\
\mathrm{E}_{1}\left[\theta \mid \hat{a}_{1}\right] & =\alpha_{2}\left(\hat{a}_{1}\right)+\phi \cdot y_{1}+\psi \cdot z,
\end{aligned}
$$

where $\alpha_{i}(\cdot)$ is a catch-all constant and $\hat{a}_{t}$ are the agent's conjectured equilibrium actions. The coefficients $\Lambda$ and $\phi$ capture the correlation between the first-period performance measures $y_{1}$ and second-period performance $y_{2}$ and managerial ability $\theta$, respectively, while controlling for the information in $z$. Similarly, the coefficients $\Gamma$ and $\psi$ capture the correlation between the noncontractible information $z$ and second-period performance $y_{2}$ and managerial ability $\theta$, respectively, while controlling for the information in $y_{1}$. We need no additional assumptions because all our results are stated in terms of $\Lambda, \Gamma, \phi$, and $\psi$ defined by (1) above, which are a sufficient characterization of the information environment for our purposes.

The career concerns model of Holmström (1999) is a particular instance of our information Siructure: there is no contractible information, but managerial ability affects the observable output, $z_{t}=\Pi_{t}=a_{t}+\theta+\zeta_{t}^{\prime}$; in our notation, $\zeta_{t}=\theta+\zeta_{t}^{\prime}$ and $\delta=\theta+\zeta_{1}^{\prime}$. In contrast to Holmström (1999), we also have contractible performance measures, and those could also be influenced by managerial ability, for example $\varepsilon_{t}=m_{\theta t} \theta+\varepsilon_{t}^{\prime}$. We assume managerial ability is a scalar, but our insights carry over to multiple dimensions of managerial ability, i.e. when $\theta$ is a multi-dimensional vector.

EXAMPLE 1. We illustrate the information structure with two tasks and two performance measures in each period and a two-dimensional non-contractible signal, so that $m=n=k=2$. The non-contractible information is $z=M a_{1}+m_{\theta} \theta+\delta^{\prime}$, where $m_{\theta}=[1,1]^{*}$ and the performance measures are $y_{t}=M_{t} a_{t}+\varepsilon_{t}$. Managerial ability $\theta$ only affects the non-contractible information $z$, $\delta=m_{\theta} \theta+\delta^{\prime}$, but not the contractible performance measures; $y_{1}$ is uncorrelated with $y_{2}$, but $z$ (or 
more precisely $\left.\delta^{\prime}\right)$ is correlated with $y_{2}$. The variance-covariance matrix of $\left(y_{2}, \theta, z\right)$ is

$$
\Sigma\left(y_{2}, \theta, z\right)=\left[\begin{array}{ccccc}
\sigma_{\varepsilon_{21}}^{2} & 0 & 0 & \gamma_{11} & \gamma_{12} \\
0 & \sigma_{\varepsilon_{22}}^{2} & 0 & \gamma_{21} & \gamma_{22} \\
0 & 0 & \sigma_{\theta}^{2} & \sigma_{\theta}^{2} & \sigma_{\theta}^{2} \\
\gamma_{11} & \gamma_{21} & \sigma_{\theta}^{2} & \sigma_{\theta}^{2}+\sigma_{\delta_{1}^{\prime}}^{2} & \sigma_{\theta}^{2} \\
\gamma_{12} & \gamma_{22} & \sigma_{\theta}^{2} & \sigma_{\theta}^{2} & \sigma_{\theta}^{2}+\sigma_{\delta_{2}^{\prime}}^{2}
\end{array}\right]
$$

It follows that $\mathrm{E}_{1}\left[y_{2}\right]=\alpha_{1}+\Gamma z, \mathrm{E}_{1}[\theta]=\alpha_{2}+\psi \cdot z ;$ thus, $\Lambda=0, \phi=0$, and

$$
\begin{aligned}
& \psi=\frac{\sigma_{\theta}^{2}}{\sigma_{\theta}^{2} \sigma_{\delta_{1}^{\prime}}^{2}+\sigma_{\theta}^{2} \sigma_{\delta_{2}^{\prime}}^{2}+\sigma_{\delta_{1}^{\prime}}^{2} \sigma_{\delta_{2}^{\prime}}^{2}}\left[\begin{array}{c}
\sigma_{\delta_{2}^{\prime}}^{2} \\
\sigma_{\delta_{1}^{\prime}}^{2}
\end{array}\right] \\
& \Gamma=\frac{1}{\sigma_{\theta}^{2} \sigma_{\delta_{1}^{\prime}}^{2}+\sigma_{\theta}^{2} \sigma_{\delta_{2}^{\prime}}^{2}+\sigma_{\delta_{1}^{\prime}}^{2} \sigma_{\delta_{2}^{\prime}}^{2}}\left[\begin{array}{cc}
\left(\gamma_{11}-\gamma_{12}\right) \sigma_{\theta}^{2}+\gamma_{11} \sigma_{\delta_{2}^{\prime}}^{2} & -\left(\gamma_{11}-\gamma_{12}\right) \sigma_{\theta}^{2}+\gamma_{12} \sigma_{\delta_{1}^{\prime}}^{2} \\
\left(\gamma_{21}-\gamma_{22}\right) \sigma_{\theta}^{2}+\gamma_{21} \sigma_{\delta_{2}^{\prime}}^{2} & -\left(\gamma_{21}-\gamma_{22}\right) \sigma_{\theta}^{2}+\gamma_{22} \sigma_{\delta_{1}^{\prime}}^{2}
\end{array}\right] .
\end{aligned}
$$

We assume contracts are linear functions of the contractible performance measures: either short-term linear contracts subject to interim participation constraints, or long-term linear contracts subject to renegotiation. The linearity of conditional expectations with normal distributions, exponential utility, and linear contracts ensure that the agent's final wealth $w$ is normally distributed and the agent has mean-variance preferences given by the certainty equivalent

$$
\mathrm{CE}_{t}(w \mid a)=\mathrm{E}_{t}[w \mid a]-\frac{1}{2} r \operatorname{var}_{t}(w)-\kappa\left(a_{1}\right)-\kappa\left(a_{2}\right)
$$

where $\mathrm{E}_{t}$ and $\operatorname{var}_{t}$ denote expectation and variance, respectively, conditional on information available at date $t=0,1$. Contracts are optimal and satisfy the participation constraints given a set of actions and associated incentive rates that implement those actions, but without making any claims as to the optimality of those induced actions from the principal's perspective, see, e.g. Christensen, Șabac, and Tian (2010). The equilibrium with optimal actions is then a particular case.

In what follows, we focus on long-term contracts because they dominate short-term contracts 
in the presence of non-contractible information. We treat short-term contracts in Appendix A and compare them to long-term contracts in Appendix B. A long-term linear contract at date $t=0$ is a take-it-or-leave-it offer by the principal $w^{I}=f_{I}+v_{I 1} \cdot y_{1}+v_{I 2} \cdot y_{2}$. Once the initial contract is accepted, we assume that the principal and the agent are committed to employment in both periods. In exchange for the commitment to employment for both periods, the principal commits to making a "fair" linear renegotiation offer at date $t=1$ to the agent, $w^{R}=f_{R}+v_{R 2} \cdot y_{2}$, where $f_{R}$ and $v_{R 2}$ may depend on $t=1$ information, see Figure 1 .
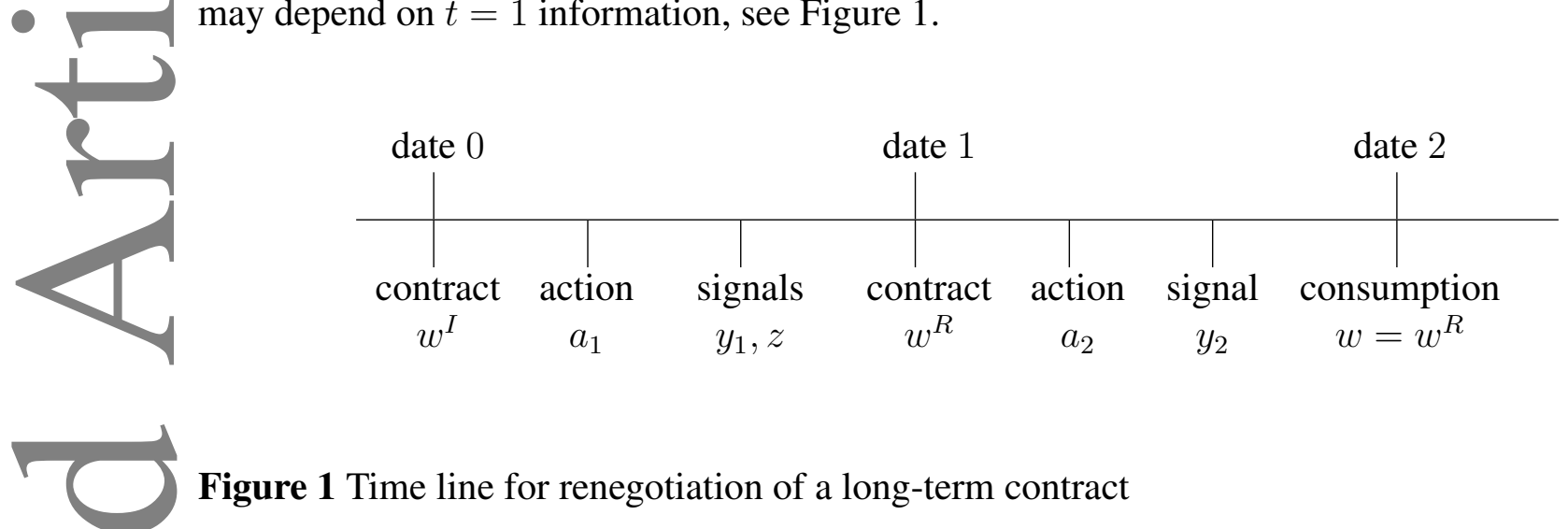

Figure 1 Time line for renegotiation of a long-term contract

The renegotiation offer introduces career concerns similar to those present with short-term contracts (Holmström 1999). That is, a fair renegotiation offer includes, in addition to the reservation certainty equivalent provided by the initial contract, a fraction $B \geq 0$ of the agent's revised expected ability. ${ }^{7}$ We exogenously assume the renegotiation offer $w^{R}$ satisfies

$$
\mathrm{CE}_{1}\left(w^{R} \mid \hat{a}_{1}, \hat{a}_{R 2}\right) \geq \mathrm{CE}_{1}\left(w^{I} \mid \hat{a}_{1}, \hat{a}_{I 2}\right)+B \mathrm{E}_{1}\left[\theta \mid \hat{a}_{1}\right]
$$

The renegotiation setup characterized by participation constraint (3) reflects the real life situation where the principal and the agent renegotiate based on what is already promised-the longterm incentives that are already vested — and the agent's revised "market value." Specifically, our

\footnotetext{
${ }^{7}$ We assume that the principal and the manager 1) commit to employment over two periods, and 2) commit to the specifics of the renegotiation process. This setting is a particular instance of renegotiation design with unverifiable information (Aghion et al. 1994). The assumed ex ante commitments made by the contracting parties, for example, the principal and the manager explicitly commit to employment over two periods (see Christensen et al. 2003), are rarely observed in practice. However, firms commit through promising severance payments and agents commit through accepting deferred compensation. If we made such assumptions, then assuming the two parties commit to employment is unnecessary while assuming the principal cannot exploit the agent is still needed.
} 
setup mirrors the common practice that 1) managers are awarded long-term incentive plans that expire perhaps ten years from the grant date but vest much earlier, often after one year (such a plan determines $v_{I 2}$ in our setup and similarly "locks-in" at vesting (date 1) some of the manager's future compensation); and 2) new long-term incentives added to $v_{I 2}$ (to get to $v_{R 2}$ ) as well as fixed compensation are negotiated each period. Further, the fixed remuneration offered to the manager depends on the manager's revised expected ability as it affects relative bargaining power. Due to the cost of changing jobs the agent (principal) may only capture a fraction $B<1$ of the full increase (decrease) in "market value" if the expectation of $\theta$ increases (decreases). ${ }^{8}$

The initial contract determines in part the renegotiation offer, but it need not be renegotiationproof. ${ }^{9}$ When accepting the initial contract, the agent rationally anticipates the renegotiation offer $w^{R}$ that determines the agent's final payoff, so the participation constraint at $t=0$ is:

$$
\mathrm{CE}\left(w^{I}, w^{R} \mid \hat{a}_{1}, \hat{a}_{2}\right) \geq 0
$$

The agent's expected ability does not affect the reservation wage at the initial date because it is ex ante normalized to zero. The participation constraints (3) and (4) determine the agent's fixed wages and are both binding in equilibrium. The participation constraints (3) and (4) are such that the long-term contract setting is equivalent to the short-term career concerns settings in which all the information is contractible as in Gibbons and Murphy (1992) and Meyer and Vickers (1997),

\footnotetext{
${ }^{8}$ When beliefs about the agent's ability are revised upward, $\mathrm{E}_{1}\left[\theta \mid \hat{a}_{1}\right]>0$, and $B>0$, the agent is strictly better off than continuing on the initial contract and this comes at the principal's cost. However, the principal always gains from renegotiating the contract to $v_{R 2}$ if $v_{I 2}$ is not optimal ex post. The net result may be that the principal is worse off than with the initial contract. Conversely, when beliefs are revised downward, the agent is worse off and the principal is always better off than continuing on the initial contract. Thus, for $B>0$, the starting point in renegotiation changes away from the continuation value of the initial contract. A better than expected agent will gain some bargaining power and a fraction of the expected gain; a worse than expected agent will have less bargaining power and will share in the expected loss. This assumed adjustment to the starting point in renegotiation is consistent with the idea that a manager's power in negotiating with the board can increase or decrease depending on whether the manager is perceived to be more or less able than expected, respectively (Hermalin and Weisbach 1998; Adams, Hermalin, and Weisbach 2010). This particular sharing of the surplus may not be ex post Pareto efficient for the principal and the agent, if we take the starting point in renegotiation to be only the initial contract, thus the exogenously assumed renegotiation design. However, the total certainty equivalent $\mathrm{TCE}_{1}(w)=\mathrm{CE}_{1}(w)+\mathrm{E}_{1}\left[\Pi_{2}-w\right]$ is ex post efficient, $\mathrm{TCE}_{1}\left(w^{R}\right) \geq \mathrm{TCE}_{1}\left(w^{I}\right)$, as long as $w^{R}$ is chosen optimally ex post. In addition, renegotiation of long-term contracts as described here dominates using short-term contracts as shown in Appendix B.

${ }^{9}$ The renegotiation-proofness principle applies when all the information is contractible and $B=0$ (see Sabac 2007). Otherwise, there will be non-trivial renegotiation of initial contracts (see, e.g., Christensen et al. 2013).
} 
see Proposition 2 in Appendix B. Additional details on interim participation constraints in career concerns models are in Appendix A.

The agent's incentive constraints in the first and second period are, respectively

$$
a_{1} \in \operatorname{argmax}_{a} \mathrm{CE}\left(w^{I}, w^{R} \mid a, \hat{a}_{2}\right) \text { and } a_{2} \in \operatorname{argmax}_{a} \mathrm{CE}_{1}\left(w^{R} \mid a_{1}, a\right) .
$$

\section{Effective incentives and implicit aggregation}

The explicit incentives in our model are the coefficients on $y_{1}$ and $y_{2}$ that determine the agent's variable compensation; that is $v_{I 1}, v_{I 2}$, and $v_{R 2}$. The implicit incentives are those that arise from any other compensation that is ex ante variable with respect to the observable information $y_{1}, z$. (The variable compensation with respect to $y_{2}$ is determined by $v_{R 2}$, and is thus entirely explicit.) The second-period fixed compensation (fixed wage $f_{R}$ in the second-period offer to renegotiate a long-term contract) is set after observing first-period performance $y_{1}$ and the non-contractible information $z$. Thus, although ex-post fixed because at date $t=1$ both $y_{1}$ and $z$ are realized, the fixed compensation $f_{R}$ is ex-ante variable at date $t=0$ with respect to $y_{1}$ and $z$. With career concerns the agent can improve the terms offered-the fixed compensation $f_{R}$-by increasing the principal's expectations of agent ability. In contrast the ratcheting effect often provides countervailing implicit incentives as the agent can improve terms offered - the fixed compensation $f_{R}$ - by lowering the principal's expectations of second period performance.

The fixed compensation $f_{R}$ offered at date $t=1$ is determined by the agent's interim participation constraint (3), based in part on renegotiation of an initial contract that the principal controls. Thus, the principal has some control over implicit incentives through the initial contract offer.

Because contract renegotiation subject to constraint (3) introduces implicit incentives, the agent faces effective (or total) incentives that consist of explicit and implicit incentives. As the principal can only control implicit incentives by controlling explicit incentive rates, we start by exogenously specifying explicit incentive rates; we then derive efficient contracts with renegotiation conditional 
on the given explicit incentive rates. This allows us to determine the ex-ante total, or effective, incentives on the contractible information (explicit plus implicit) and on the non-contractible information (implicit only). We then separate the ex-ante implicit incentives into fixed effects-that are not controllable by the principal—and controllable implicit incentives. Finally, this allows us to determine the real incentive effects of soft information.

\section{Effective incentives}

We begin by determining the effective incentives and the induced actions for exogenous explicit incentives (all necessary proofs are in Appendix C).

LEMMA 1. For given incentive rates $v_{I 1}, v_{I 2}$ and $v_{R 2}$ in a sequence of renegotiated long-term contracts $w^{I}, w^{R}$, subject to constraint (3), the agent's final/total compensation is

$$
\begin{aligned}
w^{R}=f_{I} & +v_{I 2} \cdot \alpha_{1}-v_{R 2} \cdot \alpha_{1}+B \alpha_{2} \\
& -\kappa\left(\hat{a}_{I 2}\right)-\frac{1}{2} r \operatorname{var}_{1}\left(w^{I}\right)+\kappa\left(\hat{a}_{R 2}\right)+\frac{1}{2} r \operatorname{var}_{1}\left(w^{R}\right)+v_{R 2} \cdot y_{2} \\
& \quad+\left[v_{I 1}+B \phi+\Lambda^{*}\left(v_{I 2}-v_{R 2}\right)\right] \cdot y_{1}+\left[B \psi+\Gamma^{*}\left(v_{I 2}-v_{R 2}\right)\right] \cdot z .
\end{aligned}
$$

he actions induced by the long-term contracts with explicit incentive rates $v_{I 1}, v_{I 2}$ and $v_{R 2}$ are

$$
\begin{aligned}
\nabla_{a_{1}} \kappa\left(a_{1}\right) & =M_{1}^{*} v_{1}^{e}+M^{*} v_{z}^{e} \\
& =M_{1}^{*}\left[v_{I 1}+B \phi+\Lambda^{*}\left(v_{I 2}-v_{R 2}\right)\right]+M^{*}\left[B \psi+\Gamma^{*}\left(v_{I 2}-v_{R 2}\right)\right] \\
\nabla_{a_{2}} \kappa\left(a_{2}\right) & =M_{2}^{*} v_{2}^{e}=M_{2}^{*} v_{R 2} .
\end{aligned}
$$

The effective incentive on $y_{2}$ is the same as the explicit incentive $v_{R 2}$, i.e., $v_{2}^{e}=v_{R 2}$, whereas the effective incentive on $y_{1}$ is $v_{1}^{e}=v_{I 1}+B \phi+\Lambda^{*}\left(v_{I 2}-v_{R 2}\right)$ and consists of explicit incentives $v_{I 1}$ and implicit incentives $B \phi+\Lambda^{*}\left(v_{I 2}-v_{R 2}\right)$. The effective incentive on $z$ is $v_{z}^{e}=B \psi+\Gamma^{*}\left(v_{I 2}-v_{R 2}\right)$ and is entirely implicit. The effective incentive $v_{1}^{e}$ includes the fixed effects $B \phi-\Lambda^{*} v_{R 2}$ and $v_{z}^{e}$ includes the fixed effects $B \psi-\Gamma^{*} v_{R 2}$. These are fixed effects because they are not controllable by the principal ex ante and consist of: fixed effects of career concerns, $B \phi$ or $B \psi$, and of ratchet 
effects, $-\Lambda^{*} v_{R 2}$ or $-\Gamma^{*} v_{R 2}$ (here we use ratchet effect as in Indjejikian and Nanda 1999).

The effective (implicit) incentives $v_{1}^{e}$ and $v_{z}^{e}$ include one more term, $\Lambda^{*} v_{I 2}$ and $\Gamma^{*} v_{I 2}$, respectively; neither is a fixed effect because the principal controls $v_{I 2}$. Each term represents the portion of expected total compensation that renegotiation "locks in" upon observation of first-period performance $y_{1}$ and non-contractible information $z$, respectively. The principal does not have a commitment problem with respect to $v_{I 2}$ because that is the second-period incentive rate offered in the initial contract. The fact that $v_{I 2}$ will be replaced in renegotiation by $v_{R 2}$ makes it a "free parameter" for the principal in the first period. ${ }^{10}$ Most importantly for our purposes, $v_{I 2}$ allows the principal some degree of control over the implicit incentives on $z$.

Only the first-period incentives include implicit incentives as shown in (7). But the principal can attain any effective incentive rate on the first-period performance $y_{1}$ by freely choosing $v_{I 1}$. In contrast, the space of attainable effective incentive rates on the $k$ non-contractible signals $z$ is

$$
\mathcal{V}_{z}^{e} \equiv\left\{v_{z}^{e} \in \mathbb{R}^{k} \mid v_{z}^{e}=B \psi+\Gamma^{*} x, \forall x \in \mathbb{R}^{n}\right\}
$$

The principal chooses effective incentive rates $v_{z}^{e}$ in $\mathcal{V}_{z}^{e}$ through the choice at $t=0$ of $v_{I 2} \cdot{ }^{11}$

By controlling the incentive rate $v_{I 2}$, the principal controls the difference between the incentive rates on the second-period contractible signals in the initial contract and the renegotiated contract, i.e., $x=v_{I 2}-v_{R 2}$. Consequently, the space of controllable incentives on $z$ is

$$
\mathcal{V}_{z} \equiv\left\{v_{z} \in \mathbb{R}^{k} \mid v_{z}=\Gamma^{*} x, \forall x \in \mathbb{R}^{n}\right\}
$$

${ }^{10}$ When $z$ is contractible, $v_{I 2}$ is redundant because first-period incentives can be fully controlled through the incentive rate $v_{I 1}$ on first-period performance, which in this case also includes $z$. Similarly, with short-term contracts, any fixed effects of career concerns, or the ratchet effect, can be fully neutralized through the incentive rate $v_{1}$ on first-period performance, which also includes $z$.

${ }^{11}$ If the renegotiated incentive rate $v_{R 2}$ is ex post optimal, then the total certainty equivalent is also maximized, and that ensures $\operatorname{TCE}_{1}\left(w^{R}\right) \geq \operatorname{TCE}_{1}\left(w^{I}\right)$ for any initial incentive rate $v_{I 2}$. Thus, the difference in the principal's expected utilities ex post is $\mathrm{E}_{1}\left[\Pi_{1}+\Pi_{2}-w^{R} \mid v_{R 2}\right]-\mathrm{E}_{1}\left[\Pi_{1}+\Pi_{2}-w^{I} \mid v_{I 2}\right]=\mathrm{TCE}_{1}\left(w^{R}\right)-\mathrm{TCE}_{1}\left(w^{I}\right)-B \mathrm{E}_{1}\left[\theta \mid \hat{a}_{1}\right]$. However, when choosing $v_{I 2}$ at the initial date, the principal can only evaluate this difference in utility levels in expectation, and that is positive independently of the choice of $v_{I 2}$ because $\mathrm{E}\left[\mathrm{E}_{1}\left[\Pi_{1}+\Pi_{2}-w^{R} \mid v_{R 2}\right]-\mathrm{E}_{1}\left[\Pi_{1}+\Pi_{2}-\right.\right.$ $\left.\left.w^{I} \mid v_{I 2}\right]\right]=\mathrm{E}\left[\mathrm{TCE}_{1}\left(w^{R}\right)-\mathrm{TCE}_{1}\left(w^{I}\right)\right] \geq 0$. The fixed transfer between the principal and the agent due to career concerns, $B \mathrm{E}_{1}\left[\theta \mid \hat{a}_{1}\right]$, has an expected value of zero and does not constrain the principal's choice of $v_{I 2}$. 
It follows that the principal can always "undo" the fixed incentive effect on $z$ due to the ratchet effect $-\Gamma^{*} v_{R 2}$, so the attainable effective incentives on $z$ are constrained only by the fixed incentive effects arising from career concerns, $\mathcal{V}_{z}^{e}=B \psi+\mathcal{V}_{z}$.

With short-term contracts, the first-period fixed effects are the same as with long-term contracts, see (15) in Appendix A, and the effective incentives can be obtained from those in (7) by setting $v_{I 2}=0$. With short-term contracts, the principal can also attain any effective incentive rate on the first-period performance by freely choosing explicit incentives $v_{1}$ on $y_{1}$, whereas the effective incentive on the non-contractible information $z$ is entirely determined by the fixed effects $B \phi-$ $\Lambda^{*} v_{R 2}$. Because the principal only has a degree of control over implicit incentives that arise from observing the non-contractible information $z$ under long-term contracting, long-term contracts are preferred over short-term contracts in the presence of non-contractible information. Otherwise, if $z$ were contractible, long-term and short-term contracts are equivalent: the principal can induce the same actions at the same cost. We present these results in detail in Appendix B.

\section{Effectively contractible implicit aggregation}

Feltham and Xie (1994) show how performance measures can restrict the space of incentives (for example, a single performance measure restricts incentives along a one-dimensional line determined by the sensitivities of that measure to the manager's actions). More generally, in this type of linear model, restrictions on the space of incentives can be equivalently characterized by aggregations of the available performance measures.

For example, in (8) above, controllable incentives on $z$ are restricted to vectors spanned by the rows of $\Gamma$, that is $\Gamma^{*} x$ and the corresponding incentive pay is $\Gamma^{*} x \cdot z$, where $x$ is unrestricted. But because $\Gamma^{*} x \cdot z=x \cdot \Gamma z$, we can equivalently characterize the same incentive pay as an unrestricted incentive weight $x$ on the aggregate measure $\Gamma z$. Indeed, rewriting the variable pay that depends on $z$ in equation (6), we have $v_{z}^{e} \cdot z=\left[B \psi+\Gamma^{*}\left(v_{I 2}-v_{R 2}\right)\right] \cdot z=\left(B \psi-\Gamma^{*} v_{R 2}\right) \cdot z+v_{I 2} \cdot \Gamma z$. As the principal can freely choose the incentive rate $v_{I 2}$ on the $n$-dimensional vector $\Gamma z$, the aggregate $\Gamma z$ is effectively contractible as defined below. 
DEFINITION 1. An aggregate $\Upsilon z$ of the non-contractible signals is effectively contractible if, conditional on the non-contractible information z being observable,

(a) The implementable actions $\left(a_{1}, a_{2}\right)$ are the same as if $\Upsilon z$ were directly contractible.

(b) Any implementable actions $\left(a_{1}, a_{2}\right)$ can be induced at the same cost as if $\Upsilon z$ were directly contractible.

Note, however, that an effectively contractible aggregation is fixed and entirely determined by the contractible performance measures and how they relate with the non-contractible signalssimilar in nature to contracting on stock price, which also aggregates observable information.

Effective contractibility as defined above only captures the principal's scope of control over the agent's implicit incentives based on soft information. A stronger requirement is that the effectively contractible aggregate can be substituted for the non-contractible information without affecting the agency. As we will see, this is equivalent to career concerns having no real effects.

DEFINITION 2. An effectively contractible aggregate $\Upsilon z$ is an incentive sufficient aggregate if the same actions can be implemented at the same cost when $\Upsilon z$ is observed instead of $z$.

To illustrate, consider the case depicted in Figure 2, with $m=n=k=2$ and the onedimensional row space of $\Gamma$ spanned by a vector $\Upsilon$. The principal cannot effectively contract on $z$ because the subspace $\mathcal{V}_{z}^{e}$ is one-dimensional, but $\mathcal{V}_{z}^{e}$ includes the fixed (incentive) effect $B \psi$. Here, the effective incentives on $z$ are $\mathcal{V}_{z}^{e}=\left\{v_{z}^{e} \in \mathbb{R}^{2} \mid v_{z}^{e}=B \psi+\Gamma^{*} x, \forall x \in \mathbb{R}^{2}\right\}=$ $\left\{v_{z}^{e} \in \mathbb{R}^{2} \mid v_{z}^{e}=v \psi, \forall v \in \mathbb{R}^{1}\right\}$, that is the line along the vector $\psi$ ( $\psi$ and $\Upsilon$ are collinear but of different length), and the effective incentives on $z$ are fully controllable by the principal, $\mathcal{V}_{z}^{e}=\mathcal{V}_{z}$, as depicted in Figure 2. In particular, career concerns have no real incentive effects, the only real incentive effect of observing the soft information $z$ is that the principal can effectively contract on a one-dimensional aggregation of the information in $z, \Upsilon z$. 


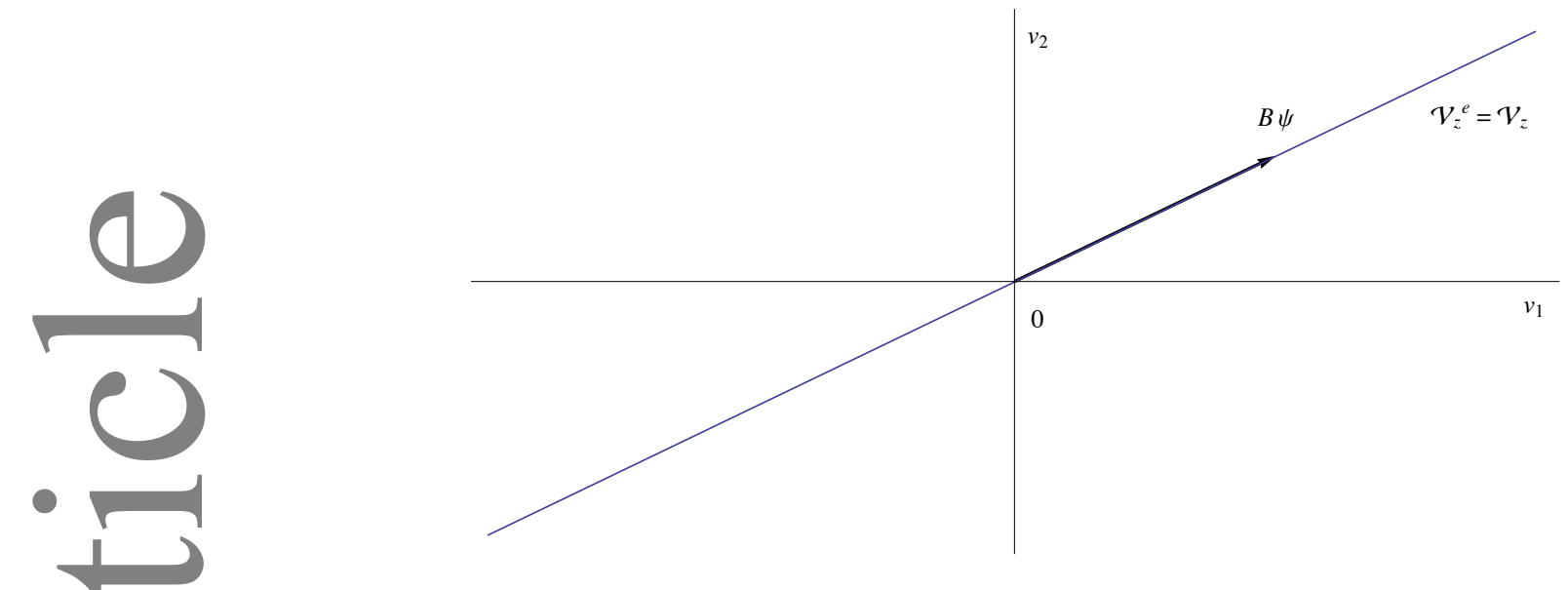

Figure 2 Attainable effective incentives on $z$ when $\psi$ is spanned by the rows of $\Gamma$

For an aggregate $\Upsilon z$ that is effectively contractible but not incentive sufficient, consider the case illustrated in Figure 3, where everything is as in Figure 2, except that $\psi$ is no longer spanned by the rows of $\Gamma$, and thus no longer collinear with $\Upsilon$. The space of attainable effective incentive rates $\mathcal{V}_{z}^{e}$ is now $\mathcal{V}_{z}$ translated by the fixed incentive effect $B \psi-\bar{v}_{z}$, equivalently $B \psi$,

$$
\mathcal{V}_{z}^{e}=\left\{v_{z}^{e} \in \mathbb{R}^{2} \mid v_{z}^{e}=B \psi+\Upsilon^{*} x, \forall x \in \mathbb{R}^{1}\right\}=B \psi-\bar{v}_{z}+\mathcal{V}_{z}=B \psi+\mathcal{V}_{z} \cdot{ }^{12}
$$

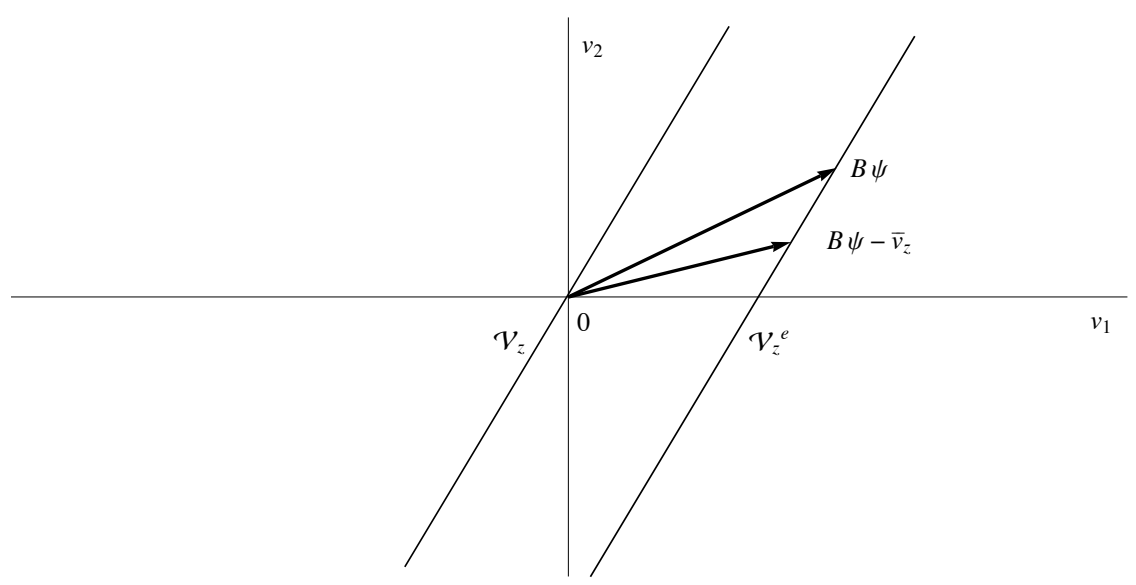

Figure 3 Attainable effective incentives on $z$ when $\psi$ is not spanned by the rows of $\Gamma$

\footnotetext{
${ }^{12}$ The vector $\Upsilon z$ is a linear combination of the columns of $\Upsilon$, whereas the vector $\Upsilon^{*} x$ is a linear combination of the columns of $\Upsilon^{*}$, that is of the rows of $\Upsilon$.
} 
Here, $\bar{v}_{z}=\Gamma^{*} v_{R 2}$ is the fixed effect that corresponds to the ratchet effect but can be compensated for because $\bar{v}_{z} \in \mathcal{V}_{z}$. The subspace $\mathcal{V}_{z}$ represents as before the incentives controllable by the principal and is depicted by the line through the origin in Figure 3. In this case, career concerns have real incentive effects; the real incentive effects of observing the soft information $z$ are that the principal can effectively contract on the one-dimensional aggregation of the information in $z, \Upsilon z$, but that is not sufficient to compensate for the fixed effects of career concerns.

In general, the space of attainable incentives on $z, \mathcal{V}_{z}^{e}$, has dimension $q=\operatorname{rank}(\Gamma) \leq \min \{k, n\}$. For example $\mathcal{V}_{z}^{e}$ has dimension $q=1$ in Figures 2 and 3. That implies the principal has only $q$ degrees of freedom in controlling incentives on $z$. Similarly, the effectively contractible aggregate $\Gamma z$ is an $n$-dimensional vector, but of the $n$ rows of $\Gamma$, only $q$ are linearly independent. That means only $q$ of the $n$ signals in $\Gamma z$ can be independent. More generally, there should be a $q$-dimensional effectively contractible aggregate that matches the principal's scope of control. This would be a "minimal" aggregation of the information in $z$ that is effectively contractible. ${ }^{13}$ We next characterize such an aggregate of $z$, including conditions such that it is an incentive sufficient aggregate. This allows a complete characterization of the real incentive effects of observing soft information.

Assume without loss of generality that the non-contractible signals are ordered such that the first $q$ columns of $\Gamma$ are linearly independent, i.e., $\Gamma=\left[\Gamma^{q}, \Gamma^{k-q}\right]$, where $\Gamma^{q}$ has rank $q$. Let $\Omega$ be the $(q \times(k-q))$-matrix that determines the columns of $\Gamma^{k-q}$ as linear combinations of the columns in $\Gamma^{q}$, i.e., $\Gamma^{k-q}=\Gamma^{q} \Omega$. As a consequence, $\Gamma=\Gamma^{q}\left[I^{q}, \Omega\right]$, where $I^{q}$ denotes the $q$-dimensional identity matrix. We define $\Upsilon:=\left[I^{q}, \Omega\right]$ so that $\Gamma=\Gamma^{q} \Upsilon$.

Proposition 1. Assume that $\Gamma$ has rank $q \leq \min \{k, n\}$.

A. The q-dimensional aggregate $\Upsilon z$ of the non-contractible signals is effectively contractible with long-term contracts, where $\Upsilon=\left[I^{q}, \Omega\right]$.

B. The aggregate $\Upsilon z$ is an incentive sufficient aggregate if, and only if, the implicit incentive caused by career concerns B $\psi$ (equivalently the vector $\psi$ ) is spanned by the rows of $\Upsilon=$

\footnotetext{
${ }^{13}$ This aggregation is "minimal" in the sense that it reduces the number of signals on which the principal controls incentives to a minimum. Sabac and Yoo (2018) consider minimal aggregation of performance measures in the different context of minimal sufficient statistics for the contractible information in a single-period multi-task agency.
} 
$\left[I^{q}, \Omega\right]$, i.e., there exists $a(q \times 1)$ vector $\pi$ such that $B \psi=\Upsilon^{*} \pi$. The total surplus is independent of career concerns $(B)$, if, and only if, $\Upsilon z$ is an incentive sufficient aggregate.

Part A of Proposition 1 characterizes the real incentive effects of soft information that are controllable by the principal: an implicit aggregation of the non-contractible information that is effectively contractible through contract renegotiation; it arises from $\Gamma z$, the portion of forecasted second-period performance that is based on the non-contractible information $z$. The principal fully controls through $v_{I 2}$ the part of the agent's final fixed compensation that depends on expected second period performance at renegotiation time, $v_{I 2} \mathrm{E}\left[y_{2} \mid \hat{a}_{1}, \hat{a}_{2}, y_{1}, z\right]$, and thus fully controls implicit incentives on $\Gamma z$. Observing the aggregate $\Gamma z$ instead of $z$ is just as good in forecasting secondperiod performance because $\mathrm{E}\left[y_{2} \mid \hat{a}_{1}, \hat{a}_{2}, y_{1}, z\right]=\alpha_{1}\left(\hat{a}_{1}, \hat{a}_{2}\right)+\Lambda y_{1}+\Gamma z=\mathrm{E}\left[y_{2} \mid \hat{a}_{1}, \hat{a}_{2}, y_{1}, \Gamma z\right]$. Similarly, the aggregate $\Upsilon z$ can always be substituted for $z$ in forecasting $y_{2}$ because $\Upsilon z$ is a sufficient statistic for $\Gamma z$ (by construction, since $\Gamma=\Gamma^{q} \Upsilon$ ). By a slight abuse of language, we also refer to $\Upsilon z$ as a forecast of future performance based on observed non-contractible information. ${ }^{14}$

If $\Gamma$ has rank $k$ (the number of soft signals), then $k \leq n$ and $z$ itself is effectively contractible, and also an incentive sufficient aggregate. Indeed, since $(k \times k)$-matrix $\Gamma \Gamma^{*}$ is invertible, the space of attainable effective incentive rates $\mathcal{V}_{z}^{e}$ is the full $k$-dimensional linear space $\mathbb{R}^{k}$, because for any $v_{z}^{p} \in \mathbb{R}^{k}$, we can find incentive rates on the second-period contractible signals $y_{2}$ in the initial contract $v_{I 2}$ such that the effective incentive rates on $z$ is $v_{z}^{e}$, i.e., $v_{I 2}=\left(\Gamma \Gamma^{*}\right)^{-1} \Gamma\left(v_{z}^{e}-B \psi\right)+v_{R 2}$. In other words, if $\Gamma$ has rank $k$, then the principal can obtain any desired effective incentive on $z$, $v_{z}$, by suitably choosing explicit incentives on the contractible second-period performances $y_{2}$ in the initial contract, i.e., $v_{I 2}$, such that the effective incentive (which includes career concerns and explicit incentives), i.e., $v_{z}^{e}=B \psi+\Gamma^{*}\left(v_{I 2}-v_{R 2}\right)$, is equal to $v_{z}$. A simple example is if $n=k=1$; then, $\Gamma$ is a scalar and (unless $y_{2}$ and $z$ are uncorrelated) $z$ is always effectively contractible.

Conversely, if $z$ is effectively contractible, then the attainable incentives on $z$ are the full space

\footnotetext{
${ }^{14}$ The forecasted second-period performance $\Gamma z$ is effectively contractible because the incentive on second-period performance $v_{I 2}$ in the initial contract sets a payment—based on expected future performance conditional on observing $z$ at the intermediate date - as part of the final renegotiated contract. By having unrestricted control of $v_{I 2}$, the principal has unrestricted control of implicit incentives on the forecast $\Gamma z$, or equivalently of implicit incentives $v=v_{I 2} \Gamma^{q}$ on $\Upsilon z$ (because $v_{I 2} \Gamma=v_{I 2} \Gamma^{q} \Upsilon$ ).
} 
$\mathbb{R}^{k}, \mathcal{V}_{z}^{e}=\mathcal{V}_{z}=\mathbb{R}^{k}$, and that implies $\Gamma$ has rank $k$ (see (8) and (9)). Consequently, $z$ is effectively contractible, if, and only if $\Gamma$ has rank $k$.

EXAMPLE 2. To illustrate the effective contractibility of $z$, assume in Example 1 above that $\gamma_{11}=$ $\gamma_{22}=\gamma \neq 0$, while $\gamma_{12}=\gamma_{21}=0$, such that the implicit aggregation is characterized by

$$
\Gamma=\frac{\gamma}{\sigma_{\theta}^{2} \sigma_{\delta_{1}^{\prime}}^{2}+\sigma_{\theta}^{2} \sigma_{\delta_{2}^{\prime}}^{2}+\sigma_{\delta_{1}^{\prime}}^{2} \sigma_{\delta_{2}^{\prime}}^{2}}\left[\begin{array}{cc}
\sigma_{\theta}^{2}+\sigma_{\delta_{2}^{\prime}}^{2} & -\sigma_{\theta}^{2} \\
-\sigma_{\theta}^{2} & \sigma_{\theta}^{2}+\sigma_{\delta_{1}^{\prime}}^{2}
\end{array}\right]
$$

In this case, the rows of $\Gamma$ are linearly independent such that $\Gamma$ has full rank equal to the number of non-contractible signals $(k=2)$ and $z$ is effectively contractible with renegotiation of long-term contracts. That is, the space of attainable effective incentive rates on the $k$ non-contractible signals $z$ is $\mathcal{V}_{z}^{e}=\left\{v_{z}^{e} \in \mathbb{R}^{2} \mid v_{z}^{e}=\Upsilon^{*} x, \forall x \in \mathbb{R}^{2}\right\}=\mathbb{R}^{2}$ (note that $\Upsilon$ is the identity matrix in this case).

On the other hand, if $\Gamma$ has rank $q<k$, the space $\mathcal{V}_{z}^{e}$ has dimension $q$ and, thus, places non-trivial restrictions on the attainable effective incentive rates on the non-contractible signals $z$. Specifically, the space of attainable effective incentive rates on $z$ is the $q$-dimensional row space of $\Gamma$ translated by the fixed effect vector $B \psi$, and is thus a $q$-dimensional affine subspace of $\mathbb{R}^{k}$ (and does not necessarily contain the null vector, as depicted in Figure 3 above).

Note that the effective contractibility of $z$ requires that there are more contractible signals than non-contractible ones, $k \leq n$. What happens if $k>n$, in other words there are more soft signals $z$ that are non-contractible relative to the contractible signals $y_{t}$ ? In this case, the most we can have is $\operatorname{rank}(\Gamma)=n<k$ so that the principal can effectively contract on $n$ independent signals based on the non-contractible information. If for example $n=2$ while $k=3$, then the principal can at most contract on two linear aggregations of $z$ such that $\mathcal{V}_{z}^{e}$ is at most a two-dimensional subspace of $\mathbb{R}^{3}$. Thus, the smaller number of contractible signals itself limits the effective contractibility of the non-contractible information. An important implication is that a necessary condition for effective contractibility of soft information is that there are enough contractible signals available. Although the mechanisms differ, we find that the usefulness of soft information is ultimately supported by the available hard information, similar to the confirmatory role of hard information in disclosure 
settings (Dye 1983; Stocken 2000; Gigler and Hemmer 2001; Șabac and Tian 2015).

Part B of Proposition 1 characterizes a necessary and sufficient condition for career concerns to have no real effects (as illustrated in Figure 2 above): that the effectively contractible implicit aggregate $\Upsilon z$ is informationally sufficient in the agency. Equivalently, the principal has sufficient control over the real incentive effects of soft information to compensate for the fixed effects of career concerns. The intuition is that $\psi \cdot z$ represents the portion of assessed managerial ability that is based on the non-contractible information $z$. When $\psi$ is spanned by the rows of $\Upsilon$ (or equivalently $\Gamma$ ), the expected managerial ability can equally well be inferred from the aggregate $\Upsilon z$ as from the non-contractible information $z$ itself. Indeed, if $\psi=\Upsilon^{*} \pi$, we have that $\psi \cdot z=\pi \cdot \Upsilon z$ and $\mathrm{E}\left[\theta \mid \hat{a}_{1}, \hat{a}_{2}, y_{1}, z\right]=\mathrm{E}\left[\theta \mid \hat{a}_{1}, \hat{a}_{2}, y_{1}, \Upsilon z\right]$. In this case, $\Upsilon z$ is simultaneously sufficient for forecasting second-period performance and for estimating managerial ability. Consequently, observing the aggregate $\Upsilon z$ can be substituted for observing $z$ without affecting the agency. Moreover, as the forecast $\Upsilon z$ is effectively contractible and sufficient for estimating managerial ability, it can also be used to undo any implicit incentives arising from career concerns.

Observing the non-contractible information $z$ has two main effects: 1) fixed effects (career concerns) arising from estimating managerial ability $\theta$; and 2) controllable incentives on an aggreation of $z$ arising from estimating future performance at contract renegotiation time. The first is due to correlation between $z$ and $\theta$ and the second is due to correlation between $z$ and $y_{2}$.

Fixed effects based on non-contractible information, such as career concerns, have real effects if, and only if, they cannot be spanned within the principal's effective scope of control over the implicit incentives based on the same non-contractible information (as illustrated in Figure 3 above). ${ }^{15}$ In other words, career concerns matter only when they arise from non-contractible information and cannot be brought under the principal's scope of control. Otherwise, career concerns do not matter, and the agency problem is equivalent to one in which the non-contractible information is substituted by a contractible incentive sufficient aggregate-instead of $z$, the contracting

\footnotetext{
${ }^{15}$ From equation (6) it can be seen that the implicit incentives arising from career concerns $B \psi$ cannot be brought under the principal's control when there is no $v_{I 2}$ such that $B \psi=\Gamma^{*} v_{I 2}=\Upsilon^{*}\left(\Gamma^{q}\right)^{*} v_{I 2}$. That is, $v_{I 2}$ cannot be chosen such that $v_{z}^{e} \cdot z=\left[B \psi+\Gamma^{*}\left(v_{I 2}-v_{R 2}\right)\right] \cdot z=\Gamma^{*} v \cdot z=v \cdot \Gamma z$, for an arbitrary $v$, and thus observing $z$ gives rise to externalities.
} 
parties observe $\Upsilon z$.

Long-term contracts may allow the principal to at least partially neutralize fixed effects from career concerns or ratcheting through implicit contracting on observed non-contractible information. Short-term contracts do not allow this and are generally dominated by long-term contracts (see Appendix B). Thus, short-term contracts are undesirable in addressing career concerns when their real effects are eliminated by long-term contracts.

\section{Empirical estimation of career concerns}

We next turn to the implications of our model for estimating career concerns arising from noncontractible information when long-term contracts are renegotiated (because long-term contracts dominate short-term contracts as shown in Appendix B). In estimating pay-performance sensitivities, it is better to focus on total managerial compensation (aggregated over time, see Șabac 2008) and effectively contractible performance information; knowing how compensation is split over time requires information that may not be available.

In general, the implemented actions and the total surplus only depend on the effective incentive rates, $v_{z}^{e}$, on the non-contractible signal, $z$, the incentive rates on the first-period contractible Ignals, $y_{1}$, and on the incentive rates on the second-period contractible signals, $y_{2}$, in the renegotiated contract at $t=1$, where the latter are independent of the incentive rates in the initial contract offered at $t=0$. In other words, the principal's decision problem at $t=0$ can be represented as choosing a long-term linear contract, $w=f+v_{1} y_{1}+v_{z} z+v_{2} y_{2}$, subject to the constraints that $v_{2}$ must equal $v_{R 2}$, and $v_{z}$ must be in the space $\mathcal{V}_{z}^{e}$ (see (8)). The principal's choice of $f$ and $v_{1}$ is otherwise only constrained by the participation and incentive compatibility constraints. In this specification, career concerns are included in $v_{z}$ and hidden from view by the constraint $v_{z} \in \mathcal{V}_{z}^{e}$.

Equivalently, the effective contractibility of $\Upsilon z$ means that the principal's decision problem at $t=0$ can be represented as choosing a long-term linear contract, $w=f+B \psi z+v_{1} y_{1}+$ $v \Upsilon z+v_{2} y_{2}$, subject only to the constraint that $v_{2}$ must equal $v_{R 2}$. The principal's choice of $f, v_{1}$, and $v$ is otherwise only constrained by the participation and incentive compatibility constraints. By 
specifying the contract in terms of $\Upsilon z$ instead of $z$, whether career concerns have real consequences becomes apparent as additional compensation that varies with $z$, namely $B \psi z$. Indeed, when career concerns have no real consequences, $\Upsilon z$ is incentive sufficient, and the principal's decision problem at $t=0$ can be represented as choosing a long-term linear contract, $w=f+v_{1} y_{1}+$ $v \Upsilon z+v_{2} y_{2}$, subject to the same constraints; there is no additional compensation that varies with $z$.

The linear structure of our model readily translates into linear regression estimates of the sensitivity of managerial incentives to both the contractible and the non-contractible information. The discussion above suggests the following linear regression of total compensation $w$ on the contractible information $y_{1}, y_{2}$, the soft information $z$, and the minimal implicitly contractible aggregate $\Upsilon z: w=f+\psi z+v_{1} y_{1}+v \Upsilon z+v_{2} y_{2}+\varepsilon$. This requires an estimation of $\Upsilon z$.

The conditional expectation $\mathrm{E}\left[y_{2} \mid \hat{a}_{1}, \hat{a}_{2}, y_{1}, z\right]=\alpha_{1}\left(\hat{a}_{1}, \hat{a}_{2}\right)+\Lambda y_{1}+\Gamma z$ suggests the linear regression $y_{2}=\alpha+\Lambda y_{1}+\Gamma z+\varepsilon$ for estimating the implicit aggregation $\Gamma z$. Specifically, this requires $n$ linear regressions, one for each performance measure $y_{2 i}, i=1, \ldots, n$ :

$$
y_{2 i}=\alpha_{i}+\sum_{j=1}^{n} \lambda_{i j} y_{1 j}+\sum_{l=1}^{k} \gamma_{i l} z_{l}+\varepsilon_{i}
$$

where the independent variables are the first-period performance measures $y_{1 j}, j=1, \ldots, n$ and the non-contractible measures $z_{l}, l=1, \ldots, k$. The coefficients on $z$ determine the matrix $\Gamma=$ $\left[\left[\gamma_{i j}\right]\right]$, where each row $i$ represents the coefficients on $z$ in one of the regressions in (10) above.

But of the $n$ variables in the vector $\Gamma z$, at most $k$ are "independent variables." By eliminating the dependent variables, one obtains a set of $q=\operatorname{rank}(\Gamma) \leq \min \{k, n\}$ independent variables $\Upsilon z$; in particular, when $q=k, \Upsilon z=z$. As described in the lead-up to Proposition 1, this elimination process requires finding the rank of $\Gamma$ and a maximal set of $q$ linearly independent columns that determine the $(n \times q)$-matrix $\Gamma^{q}=\left[\left[\gamma_{1 j}, \ldots, \gamma_{n j}\right]^{*}\right], j=1, \ldots, q$. The remaining columns of $\Gamma$ form the $(q \times(k-q))$-matrix $\Gamma^{k-q}=\left[\left[\gamma_{1 j}, \ldots, \gamma_{n j}\right]^{*}\right], j=q+1, \ldots, k$. Solving the linear system of equations $\Gamma^{k-q}=\Gamma^{q} \Omega$ determines the $(q \times(k-q))$-matrix $\Omega$. These are in fact $k-q$ systems of $n$ linear equations, one for each column of $\Omega$, that is we would have to solve for each 
$l=1, \ldots, k-q$ the linear system $\sum_{j=1}^{q} \gamma_{i j} \omega_{j l}=\gamma_{i, q+l}$ for the unknowns $\omega_{j l}, j=1, \ldots q$.

Once $\Omega$ is determined as above, $\Upsilon=\left[I^{q}, \Omega\right]$, and in particular, $\Upsilon z$ is the sequence of $q$ transformed variables $z_{j}+\sum_{l=1}^{k-q} \omega_{j l} z_{q+l}$ for $j=1, \ldots, q$. We note that this is neither a subset of the $k$ components of $z$, nor a subset of the $n$ components of the contractible aggregate $\Gamma z$, but a new contractible aggregation of $z$ reduced to its "minimal dimension" $q$.

Career concerns have real effects when $z$ has incremental explanatory power, that is, $\psi \neq 0$, in the linear regression $w=f+\psi z+v_{1} y_{1}+v \Upsilon z+v_{2} y_{2}+\varepsilon$. The coefficient $\psi$ on $z$ captures the real effects of career concerns or other fixed effects outside of the principal's control. Proposition 1 tells us how to estimate the minimal effectively contractible aggregate $\Upsilon z$, and that it is an incentive sufficient aggregate, if, and only if, the coefficient $\psi$ in the above regression is zero.

In contrast, career concerns always have real effects with short-term contracts. We discuss their estimation in Appendix A.

\section{Conclusion}

Managerial incentives combine explicit incentives arising from performance-based bonus plans, stock and option awards, and implicit incentives arising from career concerns, promotions, or turnover. Performance-relevant information affects incentives in direct and indirect ways: verifiable and contractible performance measures form the basis of explicit incentive plans (contracts), whereas unverifiable and thus non-contractible information only provides implicit incentives. In this study, we focused on the implicit incentives arising from non-contractible performance information through renegotiation of long-term contracts and career concerns. By controlling explicit incentive contracts, the principal partially controls implicit incentives.

Two ingredients make such control possible: long-term contracts and sufficiently many contractible performance measures that are correlated with the non-contractible information. The principal effectively controls incentives on an implicit aggregation of the non-contractible information, making that aggregation effectively contractible. In our model, the effectively contractible 
implicit aggregation is a forecast of future performance based on the non-contractible information.

The verifiable performance measures play a confirmatory role with respect to these forecasts and facilitate implicit contracting on them. The verifiable performance measures and long-term contracts act as implicit information aggregators in a stewardship setting that is analogous to stock prices acting as implicit information aggregators in a valuation setting. Consequently, incorporating multiple performance measures into contracts is more valuable and should be observed more often in environments with more non-contractible performance-relevant information.

Our study emphasizes that there are two sides to performance measure controllability. One side, the basis of the controllability principle (Antle and Demski 1988), refers to whether the manager's actions have any impact on the performance measures, so that the manager "controls" those performance measures. The other side is whether the principal has control over the incentives that arise from performance information. This is particularly important with non-contractible information, where the possibilities range from no control, through partial control, to effective contractibility.

We characterized conditions such that externally determined (exogenous) implicit incentives can be offset by controlling incentives on an implicit aggregation of soft information. Under such conditions, career concerns do not play a substantive role, even though the non-contractible information is not effectively contractible. ${ }^{16}$ Thus, for career concerns or similar incentive externalities to play a substantive role, the external implicit incentives must fall outside the principal's scope of control, and this generally requires multiple soft signals.

An implication of our analysis is that the key pay/performance relationship is that between total incentive compensation and the effectively contractible performance information. Career concerns may or may not have real efects, depending on whether their fixed effects are spanned by the effective incentives controlled by the principal. To estimate the effect of career concerns on managerial incentives, it is necessary to incorporate soft information in the analysis and to estimate separately the implicit aggregation that is effectively contractible.

\footnotetext{
${ }^{16} \mathrm{We}$ have also established necessary and sufficient conditions for the unverifiable information to be effectively contractible through renegotiation. They resemble the sufficient conditions in Hermalin and Katz (1991), although the models are different. In these cases, career concerns play no substantive role.
} 
Career concerns could play a different/larger role with short-term contracts, but as long-term contracts dominate short-term contracts, future analyses of career concerns should either allow for long term-contracts, or provide compelling reasons why long-term contracts are not feasible.

Career concerns play a substantive role when contracts are long-term but effective contracting is difficult, or contracts are short-term. This provides guidance to empirical researchers looking for real effects of career concerns. For example, if there is considerable variation across different managerial ranks when it comes to the richness of soft performance information and contracting horizons, career concerns are more likely to have real effects when: 1) the contract horizons are longer and soft performance information is abundant but contractible performance measures are not; and 2) when the contract horizons are short and there is some soft performance information.

\section{Appendix A: Short-term contracts and participation constraints}

\section{Short-term contracts}

A short-term contract $w_{t}$ specifies a payment $w_{t}=f_{t}+v_{t} \cdot y_{t}$ at date $t$, so with short-term contracts the agent's terminal wealth is $w=w_{1}+w_{2}$, see Figure 4 .

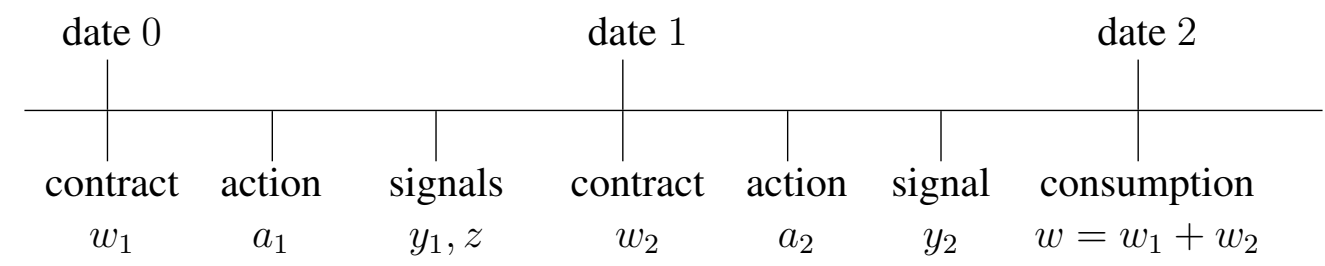

Figure 4 Time line for short-term contracts

As elsewhere in the dynamic agency and career concerns literature, we assume that, once the initial contract is accepted, the principal and the agent are committed to employment in both periods, and we specify the participation constraints exogenously. ${ }^{17}$ First, at the start of the second

\footnotetext{
${ }^{17}$ If neither the principal nor the agent can commit for several periods, there are no equilibria where the agent stays for more than one period when managerial ability is non-transferable. This problem is avoided if the agent commits to stay for multiple periods, but restrictions must be imposed on the principal at each contracting date, so the agent does
} 
period, we assume

$$
\mathrm{CE}_{1}\left(w_{2} \mid \hat{a}_{1}, \hat{a}_{2}\right) \geq B \mathrm{E}_{1}\left[\theta \mid \hat{a}_{1}\right]
$$

where $\hat{a}_{t}$ represent the actions the agent expects (or is expected by the principal) to take in equilibrium, the subscript on $\mathrm{E}_{1}$ denotes expectations conditional on date $t=1$ information, and $\theta$ is managerial ability. As we further explain below, the parameter $0 \leq B \leq 1$ exogenously specifies the impact of perceived managerial ability on the agent's reservation certainty equivalent and is determined by the relative bargaining power of the agent and the principal.

Second, the agent's participation constraint at the initial date is

$$
\mathrm{CE}\left(w_{1}+w_{2} \mid \hat{a}_{1}, \hat{a}_{2}\right) \geq 0
$$

The agent's expected ability does not affect the reservation wage at the initial date because it is $e x$ ante normalized to zero. The participation constraints (11) and (12) determine the agent's fixed wages and are both binding in equilibrium.

The agent's incentive constraints in the first and second period are, respectively

$$
a_{1} \in \operatorname{argmax}_{a} \mathrm{CE}\left(w_{1}+w_{2} \mid a, \hat{a}_{2}\right) \text { and } a_{2} \in \operatorname{argmax}_{a} \mathrm{CE}_{1}\left(w_{2} \mid a_{1}, a\right) .
$$

\section{Participation constraints}

Our participation constraints include as particular cases several settings used in the literature in the context of career concerns. The case $B=1$ corresponds to the career concerns model of Holmström (1999), in which the agent captures the expected value of his ability. Specifically, in these types of models, the agent is risk-neutral and the wage in each period is equal to the

not commit to slavery. Commitment to employment in both periods reflects common executive compensation practices that include deferred compensation forfeited by managers when leaving before the end of the contract term (which commits the manager) and "golden parachutes" that specify payments to managers if their employment is terminated early (which commit the firm). For an analysis without such commitment, see, for example, Christensen et al. (2003). 
expectation of managerial ability at the start of the period, $w_{t}=\mathrm{E}_{t-1}\left[\theta \mid \hat{a}_{t}\right]$; the only performance information available to the labour market is the output in each period, $\Pi_{t}=a_{t}+\theta+\zeta_{t}$. Thus, if we further impose the restriction $v_{t}=0$, that is, the agent only receives a fixed wage, we get exactly a two-period version of Holmström's model. A multi-task version of the Holmström career concerns model is analyzed by Dewatripont et al. (1999), who allow $w_{t}=\mathrm{E}\left[\theta \mid z_{t-1}, \hat{a}_{t}\right]$ for a vector of tasks $\hat{a}_{t}$, an arbitrary vector of non-contractible signals $z_{t-1}$, and a scalar managerial ability parameter $\theta$.

The case $B=0$ corresponds to the fair contracts in Indjejikian and Nanda (1999) and Christensen et al. (2003), in which the principal captures all the surplus. In this case, the agent's reservation certainty equivalent is zero at each date $t=1,2$.

To include settings considered in the literature that incorporate surplus sharing by the agent, the participation constraints at the interim and initial dates can be generalized to

$$
\begin{aligned}
& \left(1-B_{2}\right) \mathrm{CE}_{1}\left(w_{2} \mid \hat{a}_{1}, \hat{a}_{2}\right) \geq B_{1} \mathrm{E}_{1}\left[\theta \mid \hat{a}_{1}\right]+B_{2} \mathrm{E}_{1}\left[\Pi_{2}-w_{2} \mid \hat{a}_{1}, \hat{a}_{2}\right] \text { and } \\
& \left(1-B_{2}\right) \mathrm{CE}\left(w_{1}+w_{2} \mid \hat{a}_{1}, \hat{a}_{2}\right) \geq B_{2} \mathrm{E}\left[\Pi_{1}+\Pi_{2}-\left(w_{1}+w_{2}\right) \mid \hat{a}_{1}, \hat{a}_{2}\right], \text { respectively. }
\end{aligned}
$$

Here $B_{2}$ exogenously specifies the division of expected surplus between the agent and the principal. These generalized participation constraints include the following additional settings from the interature.

First, $B_{1}=0, B_{2}=1$ corresponds to Gibbons and Murphy (1992), in which the agent captures the entire surplus. In Gibbons and Murphy (1992), with $B_{1}=0, B_{2}=1$, we get $\mathrm{E}_{1}\left[w_{2}\right]=\mathrm{E}_{1}\left[\Pi_{2}\right]$ and $\mathrm{E}\left[w_{1}+w_{2}\right]=\mathrm{E}\left[\Pi_{1}+\Pi_{2}\right]$ because the agent's expected wage cannot exceed the principal's expected benefit and, in this case equals the expected benefit due to assumed perfect competition between principals.

Second, $B_{1}=0, B_{2}=b \in[0,1]$ corresponds to Meyer and Vickers (1997), in which the principal and the agent share the surplus. In Meyer and Vickers (1997, 559-563), the agent's second-period reservation certainty equivalent is bounded from below by a share $b$ of the total certainty equivalent $\mathrm{TCE}_{1}=\mathrm{CE}_{1}\left(w_{2}\right)+\mathrm{E}_{1}\left[\Pi_{2}-w_{2}\right]$, that is, the total between the agent's certainty equivalent and the principal's expected benefit net of compensation costs; in other words, this is the 
"total pie" available for sharing and $b$ can be thought of as the agent's exogenous bargaining power. At the initial date, Meyer and Vickers (1997) assume a fixed reservation certainty equivalent, that is, $b=0$. Since the parameter $B_{2}$ in our model, which corresponds to the bargaining power $b$ in their model, is exogenous, we assume for consistency the same value of $B_{2}$ in both participation constraints. This makes the model consistent with the one in Gibbons and Murphy (1992), in which $B_{2}=1$ at both dates.

The general formulation of the interim participation constraint combines managerial human capital and external labour market influences through the parameter $B_{1}$ and sharing of the surplus between principal and agent through the parameter $B_{2}$. However, as implicit incentives arising from surplus sharing are qualitatively similar to those arising from career concerns, we restrict attention only to the latter by setting $B_{2}=0$.

In many of the above models, the output is the only contractible performance measure. In the present study we distinguish between the performance measures $y_{t}$ and the output $\Pi_{t}$, but we can include as particular cases the studies above in which the output is the only contractible performance measure, that is $y_{t}=\Pi_{t}$, as well as a more general case in which the output $\Pi_{t}$ is only one of the available performance measures.

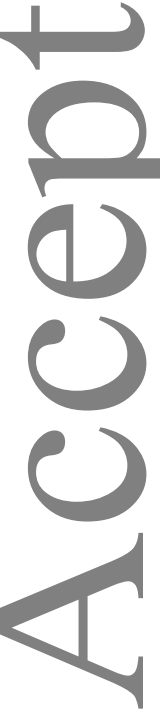

\section{Participation constraints in renegotiation of long-term contracts}

As noted in the presentation of the main model, we assume a renegotiation design for the case of long-term contracts such that, absent unverifiable information, the two settings of long-term and short-term contracts can implement the same actions at the same cost (Proposition 2 in Appendix B). For the more general case with surplus sharing discussed above, the participation constraints for renegotiation of long-term contracts are

$$
\begin{aligned}
& \mathrm{CE}_{1}\left(w^{R} \mid \hat{a}_{1}, \hat{a}_{2}\right) \geq \mathrm{CE}_{1}\left(w^{I} \mid \hat{a}_{1}, \hat{a}_{2}\right)+B_{1} \mathrm{E}_{1}\left[\theta \mid \hat{a}_{1}\right]+B_{2} \mathrm{TCE}_{1}\left[w^{R} \mid \hat{a}_{1}, \hat{a}_{2}\right] \text { and } \\
& \mathrm{CE}\left(w^{I}, w^{R} \mid \hat{a}_{1}, \hat{a}_{2}\right) \geq B_{2} \mathrm{TCE}\left[w^{I}, w^{R} \mid \hat{a}_{1}, \hat{a}_{2}\right], \text { respectively. }
\end{aligned}
$$


Here $\operatorname{TCE}_{1}\left(w^{R}\right)=\mathrm{CE}_{1}\left(w^{R}\right)+\mathrm{E}_{1}\left[\Pi_{2}-w^{R}\right]$ and $\operatorname{TCE}\left(w^{I}, w^{R}\right)=\operatorname{CE}\left(w^{R}\right)+\mathrm{E}_{1}\left[\Pi_{1}+\Pi_{2}-w^{R}\right]$, because the final contract $w^{R}$ is rationally anticipated at the initial date. To simplify the exposition, we have assumed throughout that $B_{2}=0$ and $B_{1}=B$.

Note that, at the interim date, the agent's participation constraint is of the form $\mathrm{CE}_{1}\left(w^{R}\right) \geq$ $\mathrm{CE}_{1}\left(w^{I}\right)+\Delta$, where $\Delta=B \mathrm{E}_{1}\left[\theta \mid \hat{a}_{1}\right]$ amounts to an ex-post fixed transfer from the principal to the agent (for $\Delta>0$ ) or from the agent to the principal (for $\Delta<0$ ). The total surplus $\mathrm{TCE}_{1}(w)=\mathrm{CE}_{1}(w)+\mathrm{E}_{1}\left[\Pi_{1}+\Pi_{2}-w\right]$ is independent of the transfer $\Delta$, so $\Delta$ only shifts the starting point in renegotiation away from the continuation value of the initial contract: in the agent's favour when $\Delta>0$ and in the principal's favour when $\Delta<0$. This assumed adjustment to the starting point in renegotiation is consistent with the idea that a manager's power in negotiating with the board can increase or decrease depending on whether the manager is perceived to be more or less able than expected, respectively (Hermalin and Weisbach 1998, Adams, Hermalin, and Weisbach 2010).

At renegotiation time, the principal optimizes $\mathrm{E}_{1}\left[\Pi_{2}-w^{R} \mid \hat{a}_{1}, \hat{a}_{R 2}\right]$. Consequently, the total surplus is also optimized and independent of $\Delta$, such that $\operatorname{TCE}_{1}\left(w^{R}\right) \geq \operatorname{TCE}_{1}\left(w^{I}\right)$.

\section{Fffective incentives}

The explicit incentives in short-term contracts are $v_{1}, v_{2}$. The implicit incentives are any additional compensation that is ex ante variable with respect to the observable information $y_{1}, z$. All the variable compensation with respect to $y_{2}$ is determined by $v_{2}$ and is thus entirely explicit. Second-period fixed payments (fixed wages in the second-period contract $f_{2}$ ) are set after observing first-period performance $y_{1}$ and the non-contractible information $z$. Thus, although ex-post fixed because at date $t=1$ both $y_{1}$ and $z$ are realized, such payments are ex-ante variable at date $t=0$ with respect to $y_{1}$ and $z$.

Lack of commitment means the principal cannot commit ex-ante to fixed wages offered at date $t=1$; these are determined by the agent's interim participation constraint (11). With short-term contracts, the interim participation constraint (11) is determined only by factors exogenous to the 
agency (such as labour markets); the principal has then no influence over the implicit incentives pertaining to $z$.

Because short-term contracts with interim participation constraint (11) introduce implicit incentives, the agent faces effective (or total) incentives that consist of explicit and implicit incentives. Because the principal can only control implicit incentives by controlling explicit incentive rates, we start by exogenously specifying explicit incentive rates; we then derive efficient shortterm contracts conditional on the given explicit incentive rates. This allows us to determine the ex-ante total, or effective, incentives on the contractible information (explicit plus implicit) and on the non-contractible information (implicit only). We then separate the ex-ante implicit incentives into fixed incentive effects that are not controllable by the principal and controllable implicit incentives.

Our focus is the ex ante controllability by the principal of implicit incentives on the noncontractible information $z$. That is because the principal can fully control total incentives on $y_{1}$ through the first-period explicit incentives, and can adjust for the expected implicit incentives on $y_{1}$; but that is no longer the case with the implicit incentives on $z$.

We next determine the effective incentives and the induced actions for exogenously specified xplicit incentives (all necessary proofs are in Appendix C).

LEMMA 2. For given incentive rates $v_{1}, v_{2}$ in a sequence of short-term contracts $w_{1}, w_{2}$, the agent's total compensation is

$$
\begin{aligned}
w_{1}+w_{2}= & f_{1}+v_{1} \cdot y_{1}+f_{2}+v_{2} \cdot y_{2} \\
= & f_{1}- \\
& v_{2} \cdot \alpha_{1}+B \alpha_{2}+\kappa\left(\hat{a}_{2}\right)+\frac{1}{2} r \operatorname{var}_{1}\left(w_{2}\right) \\
& \quad+\left(v_{1}+B \phi-\Lambda^{*} v_{2}\right) \cdot y_{1}+\left(B \psi-\Gamma^{*} v_{2}\right) \cdot z+v_{2} \cdot y_{2} .
\end{aligned}
$$

The actions induced by the short-term contracts with explicit incentive rates $v_{1}$ and $v_{2}$ are

$$
\begin{aligned}
& \nabla_{a_{1}} \kappa\left(a_{1}\right)=M_{1}^{*} v_{1}^{e}+M^{*} v_{z}^{e}=M_{1}^{*}\left(v_{1}+B \phi-\Lambda^{*} v_{2}\right)+M^{*}\left(B \psi-\Gamma^{*} v_{2}\right) \\
& \nabla_{a_{2}} \kappa\left(a_{2}\right)=M_{2}^{*} v_{2}^{e}=M_{2}^{*} v_{2} .
\end{aligned}
$$


As noted, the implicit incentives arise from the fixed second-period wage $f_{2}$ that is set to satisfy the interim participation constraint (11). With short-term contracts, the effective incentive $v_{2}^{e}$ on $y_{2}$ is the same as the explicit incentive $v_{2}$, i.e., $v_{2}^{e}=v_{2}$. In contrast, the effective incentive on $y_{1}$ is $v_{1}^{e}=v_{1}+B \phi-\Lambda^{*} v_{2}$ and consists of the explicit incentive $v_{1}$, and an implicit incentive including two first-period fixed effects: a fixed effect of career concerns $B \phi$, and a ratchet effect $-\Lambda^{*} v_{2}$ due to the inter-temporal correlation of the performance measures. Thus, if $B>0$ and $\phi>0$, career concerns increase the agent's effective first-period incentives, whereas-with positively correlated performance measures - the ratchet effect reduces the effective first-period incentives.

We refer to these as fixed effects because at the start of the first period when $w_{1}$ is set, they are either exogenously fixed by the contracting environment (career concerns) or depend on secondperiod decisions the principal cannot commit to and must rationally anticipate (in this case the ratchet effect is due to anticipated second-period incentives).

The implicit incentive $v_{z}^{e}=B \psi-\Gamma^{*} v_{2}$ also consists of two fixed effects: a fixed effect of career concerns $B \psi$ and a ratchet effect $-\Gamma^{*} v_{2}$ due to the inter-temporal correlation of $z$ with the second-period performance measures. As with the effective first-period incentives above, if $B>0$ and $\psi>0$, career concerns increase the implicit incentives on the non-contractible infrormation $z$, whereas - with positively correlated second-period performance and non-contractible information-the ratchet effect reduces the implicit incentives on $z$.

The empirical estimation of career concerns in this case is similar to that under long-term contracting. Based on (14) in Lemma 2, one starts by estimating a regression of second-period compensation on all the performance information: $w_{2}=\alpha+\beta_{1} y_{1}+v_{2} y_{2}+\beta_{2} z+\varepsilon$. The real effects of career concerns are included in the coefficient for the non-contractible information $\beta_{2}$. That is because any effects of observing $y_{1}$ on second-period compensation can be neutralized ex ante through the explicit first-period incentive on $y_{1}$. Using the separate estimate of $\Gamma$ from the regression $y_{2}=\alpha+\Lambda y_{1}+\Gamma z+\varepsilon$ allows backing out the career concerns $B \psi z$ from $\beta_{2} z=$ $B \psi z-v_{2} \Gamma z$. 


\section{Appendix B: Short-term vs. long-term contracts}

It is not surprising that, when all information at date $t=1$ is contractible, the implicit incentives can all be undone and the short-term and long-term contract settings are equivalent.

PROPOSITION 2. Assume all available performance information consists of the contractible performance measures $y_{1}$ and $y_{2}$, and consider the two contract settings with either a sequence of short-term contracts subject to the participation constraint (11) or a long-term contract subject to the renegotiation constraint (3). Then, any actions $\left(a_{1}, a_{2}\right)$ that can be implemented in one of the two contract settings can be implemented in the other setting with the same effective incentive rates for the two performance measures $y_{1}$ and $y_{2}$, and at the same cost. The total surplus is the same in both contract settings, and it is independent of career concerns (B).

Proposition 2 generalizes similar results in Gibbons and Murphy (1992) and Meyer and Vickers (1997), who focus on short-term contracts with only contractible performance measures. It establishes that in both the short- and long-term contract settings, the implicit incentives arising from career concerns and surplus sharing do not play a substantive role when all information is contractible. The optimal effective incentives for given actions and, consequently, the total surplus, are independent of the parameter $B$. The explicit incentives may differ between short- and long-term contracts, but the effective incentives are the same, and only these determine the total surplus.

When the information available to the labour market is also directly contractible and, thus, can be included in incentive contracts, inefficient incentives arising from the agent's career concerns (such as myopia) can be fully mitigated by the principal via explicit incentives. Then, career concerns have no real consequences - it is only a matter of how effective incentives are allocated between explicit and implicit incentives. But the labour market may rely on performance-relevant information that is not directly contractible and, thus, cannot be directly included in incentive contracts. Non-contractible information opens the door for career concerns to have real consequences, and renegotiation of long-term contracts facilitates implicit contracting on such information. 
The implicit incentive on $z$ with short-term contracts, i.e., $v_{z}^{e}=B \psi-\Gamma^{*} v_{2}$, is a single vector in the space $\mathcal{V}_{z}^{e}$ (see (8)) of attainable incentives under long-term contracting and cannot be controlled by the principal. The second-period incentive $v_{2}$ is set after $z$ is observed and, thus, is entirely determined by the posterior beliefs at $t=1$. In other words, the principal cannot control either the relative weights in the aggregation of the signals $z$ or the intensity applied to this aggregation. With short-term contracts, the non-contractible signals create a fixed incentive effect which cannot be mitigated by the principal. This leads to the following result.

PROPOSITION 3. The non-contractible signals $z$ are not effectively contractible with short-term contracts, the total surplus depends on career concerns, and the principal strictly prefers long-term contracts to short-term contracts (except in knife-edge cases).

EXAMPLE 3. To illustrate, consider Example 1 with $\gamma_{11}=\gamma_{22}=\gamma \neq 0$ and $\gamma_{12}=\gamma_{21}=0$, such that $\Gamma$ has full rank $k=2$, and $z$ is effectively contractible with long-term contracts. But $z$ is not effectively contractible with short-term contracts because the implicit incentive on $z$ is $v_{z}^{e}=B \psi-\Gamma^{*} v_{2}$ and is a fixed effect that the principal cannot control. Consequently, long-term contracts dominate short-term contracts. Effectively contracting on $z$ enables the principal to: 1) undo any fixed effect arising from career concerns; 2) improve congruity as the principal can offer any relative incentive weights on the performance measures when the manager undertakes two tasks (as long as the vectors $M_{1}$ and $M$ are not collinear); and 3) improve risk sharing. ${ }^{18}$

Conditional on $z$ being observed, the possibility of writing long-term contracts is generally advantageous because long-term contracts allows for more possibilities and is independent of whether $z$ is effectively contractible or not. In Figure 3, the vector $\bar{v}_{z}^{e}=B \psi-\bar{v}_{z}$ represents the fixed incentive on $z$ that the principal cannot control with short-term contracts, whereas $\mathcal{V}_{z}^{e}$ is the space of attainable incentives with long-term contracts. Whether it is optimal to observe $z$ in the first place is another matter as the implicit incentives on $z$ can work to the advantage as well as to the disadvantage of the agency.

\footnotetext{
${ }^{18}$ If all signals, $z$ and the performance measures $y_{t}$ in each period, are single dimensional, then $z$ is effectively contractible if $\operatorname{cov}\left(y_{2}, z\right) \neq 0$ because the rank of $\Gamma$ is one. Thus, when signals are single-dimensional, career concerns play a role only if $\operatorname{cov}\left(y_{2}, z\right)=0$ or if long-term contracting is disallowed.
} 
Observing $z$ has a negative effect if contracts are short-term and $M=M_{2}=0$ (such that $v_{R 2}=0$ ). In this case, the updating of beliefs pertaining to $\theta$ introduces uninsurable career risk, $B \psi \cdot z$, without supplying incentives for first-period effort. Consequently, mandatory disclosure of $z$ is detrimental to economic efficiency under these assumptions as in Autrey et al. (2007). However, if $z$ is effectively contractible through long-term contracts ( $\Gamma$ or $\Upsilon$ is of full rank $k$ ), then this conclusion is reversed, and thus the ranking of information systems will depend on whether short- or long-term contracts are used..$^{19}$

We conclude that long-term contracts with career concerns at renegotiation time dominate short-term contracts either because they allow a larger space of implementable actions, or because the same actions can be implemented at a lower risk premium. In both cases, the main factor is that long-term contracts allow better control of the effective (implicit) incentives on the non-contractible signals $z$ through renegotiation of the initial contract.

Taken together, Propositions 2 and 3 imply that, for career concerns to have real consequences for the agent's actions and the principal's outcome, there has to be non-contractible information that is not effectively contractible, or there have to be exogenous constraints that require shortterm contracts. Otherwise, career concerns only impact explicit incentives without having any real bnsequences for total incentives.

\footnotetext{
${ }^{19}$ The value of information rationing under renegotiation as a partial remedy for lack of commitment has been extensively studied but is outside the scope of our study. See, for example, Demski (1998), Demski and Frimor (1999), Indjejikian and Nanda (1999), Christensen, Demski, and Frimor (2002), Christensen et al. (2003, 2005), Arya and Mittendorf (2011), and Christensen et al. (2013). A ranking of information systems under renegotiation of long-term contracts when all information is contractible is presented in Șabac (2015).
} 


\section{Appendix C: Proofs}

PROOF OF LEMMA 1. For given incentive rates $v_{I 1}, v_{I 2}$ and $v_{R 2}$, the renegotiation constraint (3) is binding and determines the fixed wage in the renegotiation offer $w^{R}=f_{R}+v_{R 2} \cdot y_{2}$ :

$$
\begin{aligned}
f_{R}=f_{I}-\kappa\left(\hat{a}_{I 2}\right)-\frac{1}{2} r \operatorname{var}_{1}\left(w^{I}\right)+\kappa\left(\hat{a}_{R 2}\right)+\frac{1}{2} r \operatorname{var}_{1}\left(w^{R}\right)+v_{I 1} \cdot y_{1} \\
\quad+v_{I 2} \cdot \mathrm{E}_{1}\left[y_{2} \mid \hat{a}_{1}, \hat{a}_{I 2}\right]-v_{R 2} \cdot \mathrm{E}_{1}\left[y_{2} \mid \hat{a}_{1}, \hat{a}_{R 2}\right]+B \mathrm{E}_{1}\left[\theta \mid \hat{a}_{1}\right] .
\end{aligned}
$$

Substituting in the conditional expectations (1) and gathering the terms that depend on $y_{1}$ we have

$$
\begin{aligned}
f_{R}=f_{I} & +v_{I 2} \cdot \alpha_{1}\left(\hat{a}_{1}, \hat{a}_{I 2}\right)-v_{R 2} \cdot \alpha_{1}\left(\hat{a}_{1}, \hat{a}_{R 2}\right)+B \alpha_{2} \\
& -\kappa\left(\hat{a}_{I 2}\right)-\frac{1}{2} r \operatorname{var}_{1}\left(w^{I}\right)+\kappa\left(\hat{a}_{R 2}\right)+\frac{1}{2} r \operatorname{var}_{1}\left(w^{R}\right) \\
& +\left[v_{I 1}+B \phi+\Lambda^{*}\left(v_{I 2}-v_{R 2}\right)\right] \cdot y_{1}+\left[B \psi+\Gamma^{*}\left(v_{I 2}-v_{R 2}\right)\right] \cdot z .
\end{aligned}
$$

The renegotiation offer is then $w^{R}=f_{R}+v_{R 2} \cdot y_{2}$ and is given by (6). It follows that the actions induced by a long-term contract subject to the renegotiation constraint (3) are given by (7).

ProOF OF PROPOSITION 1. We first show that $\Upsilon z$ is effectively contractible. Since $\Gamma=\Gamma^{q} \Upsilon$, the row space of $\Gamma$ is the same as the $q$-dimensional row space of $\Upsilon=\left[I^{q}, \Omega\right]$ because

$$
\begin{aligned}
\mathcal{V}_{z} & =\left\{v \in \mathbb{R}^{k} \mid v=\left(\Gamma^{q} \Upsilon\right)^{*} x, \forall x \in \mathbb{R}^{n}\right\}=\left\{v \in \mathbb{R}^{k} \mid v=\Upsilon^{*}\left(\Gamma^{q}\right)^{*} x, \forall x \in \mathbb{R}^{n}\right\} \\
& =\left\{v \in \mathbb{R}^{k} \mid v=\Upsilon^{*} x, \forall x \in \mathbb{R}^{q}\right\}
\end{aligned}
$$

where the last equality follows from the fact that $\Gamma^{q}$ has full column rank $q$. It follows that, for any incentive weight on $z$ that the principal can fully control, $v=\Gamma^{*} v_{I 2}$, there exists $x \in \mathbb{R}^{q}$ such that $v=\Upsilon^{*} x$. In other words, $v \cdot z=\Gamma^{*} v_{I 2} \cdot z=\Upsilon^{*} x \cdot z$, or equivalently $v \cdot z=v_{I 2} \cdot \Gamma z=x \cdot \Upsilon z$. Thus, $\Upsilon z$ is effectively contractible.

To determine whether $\Upsilon z$ is a sufficient incentive aggregate, we need to determine whether the effective incentives attainable on $z$ are affected by replacing $z$ with $\Upsilon z$. First, we note that the 
posterior beliefs about $y_{2}$ at renegotiation time do not change if we replace $z$ by $\Upsilon z$. To see this, it suffices to prove that $\mathrm{E}\left[y_{2} \mid z, y_{1}\right]=\mathrm{E}\left[y_{2} \mid \Upsilon z, y_{1}\right]$ because then the conditional variances are also the same, $\operatorname{var}\left(y_{2} \mid z, y_{1}\right)=\operatorname{var}\left(y_{2}-\mathrm{E}\left[y_{2} \mid z, y_{1}\right]\right)=\operatorname{var}\left(y_{2}-\mathrm{E}\left[y_{2} \mid \Upsilon z, y_{1}\right]\right)=\operatorname{var}\left(y_{2} \mid \Upsilon z, y_{1}\right)$.

Since $\mathrm{E}\left[y_{2} \mid z, y_{1}\right]=\alpha_{1}+\Lambda y_{1}+\Gamma z$, we can write $y_{2}=\alpha_{1}+\Lambda y_{1}+\Gamma z+\left(y_{2}-\mathrm{E}\left[y_{2} \mid z, y_{1}\right]\right)$. Taking conditional expectations with respect to $\left(\Upsilon z, y_{1}\right)$ yields

$$
\mathrm{E}\left[y_{2} \mid \Upsilon z, y_{1}\right]=\mathrm{E}\left[\alpha_{1}+\Lambda y_{1}+\Gamma z \mid \Upsilon z, y_{1}\right]+\mathrm{E}\left[\left(y_{2}-\mathrm{E}\left[y_{2} \mid z, y_{1}\right]\right) \mid \Upsilon z, y_{1}\right]
$$

Because $\Gamma=\Gamma^{q} \Upsilon$, it follows that $\mathrm{E}\left[\alpha_{1}+\Lambda y_{1}+\Gamma z \mid \Upsilon z, y_{1}\right]=\alpha_{1}+\Lambda y_{1}+\Gamma^{q} \Upsilon z=\mathrm{E}\left[y_{2} \mid z, y_{1}\right]$. To complete the proof that $\mathrm{E}\left[y_{2} \mid z, y_{1}\right]=\mathrm{E}\left[y_{2} \mid \Upsilon z, y_{1}\right]$, note that $\mathrm{E}\left[\left(y_{2}-\mathrm{E}\left[y_{2} \mid z, y_{1}\right]\right) \mid \Upsilon z, y_{1}\right]=0$ by the law of iterated expectations. Indeed, writing the conditional expectations with respect to the $\sigma$-algebras generated by the available information, we note that $\sigma\left(\Upsilon z, y_{1}\right) \subseteq \sigma\left(z, y_{1}\right)$ holds generally for any matrix $\Upsilon$ and implies that $\mathrm{E}\left[\mathrm{E}\left[y_{2} \mid \sigma\left(z, y_{1}\right)\right] \mid \sigma\left(\Upsilon z, y_{1}\right)\right]=\mathrm{E}\left[y_{2} \mid \sigma\left(\Upsilon z, y_{1}\right)\right]$.

It follows that, absent career concerns, $B=0$, the effective incentives attainable on $z$ are the same with observing $\Upsilon z$ as with observing $z$. Indeed, $\mathcal{V}_{z}^{e}$ is the row space of $\Gamma$, and that is the same as the $q$-dimensional row space of the aggregation matrix $\Upsilon=\left[I^{q}, \Omega\right]$. It follows that $\mathcal{V}_{z}^{e}$ is the same with the non-contractible information $z$ as it is with a contractible aggregate $\Upsilon z$. Consequently, $\Upsilon z$ is an incentive sufficient aggregate.

Consider next the setting in Proposition 1, when the implicit incentive from career concerns $B \psi$ is non-zero, but is spanned by the rows in $\Upsilon$, i.e., there exists a vector $\pi \in \mathbb{R}^{q}$ such that $B \psi=\Upsilon^{*} \pi$. Then, $\mathcal{V}_{z}^{e}$ is the $q$-dimensional row space of the aggregation matrix $\Upsilon=\left[I^{q}, \Omega\right]$, since

$$
\begin{aligned}
\mathcal{V}_{z}^{e} & =\left\{v_{z}^{e} \in \mathbb{R}^{k} \mid v_{z}^{e}=\Upsilon^{*} \pi+\left(\Gamma^{q} \Upsilon\right)^{*} x, \forall x \in \mathbb{R}^{n}\right\}=\left\{v_{z}^{e} \in \mathbb{R}^{k} \mid v_{z}^{e}=\Upsilon^{*}(x+\pi), \forall x \in \mathbb{R}^{q}\right\} \\
& =\left\{v_{z}^{e} \in \mathbb{R}^{k} \mid v_{z}^{e}=\Upsilon^{*} x, \forall x \in \mathbb{R}^{q}\right\}
\end{aligned}
$$

where the second equality follows from the fact that $\Gamma^{q}$ has full column rank $q$, and the last equality follows from the fact that the sum of any two vectors in $\mathbb{R}^{q}$ also is in $\mathbb{R}^{q}$. In other words, any impact of implicit incentives due to career concerns can be neutralized if these are linearly dependent on 
the aggregate $\Upsilon z$ of the non-contractible signals. Thus, the principal's decision problem at $t=0$ can be represented as choosing a long-term linear contract, $w=f+v_{1} y_{1}+v \Upsilon z+v_{2} y_{2}$, subject only to the constraint that $v_{2}$ must equal $v_{R 2}$. Everything is as if there are no implicit incentives, and $\Upsilon z$ is an incentive sufficient aggregate. ${ }^{20}$

Now turn to the setting in Proposition 1 when the fixed eeffect caused by career concerns $B \psi$ is not spanned by the rows of $\Upsilon$. Then, $\mathcal{V}_{z}^{e}$ is the $q$-dimensional row space of the aggregation matrix $\Upsilon=\left[I^{q}, \Omega\right]$ translated by the fixed effect because

$$
\begin{aligned}
\mathcal{V}_{z}^{e} & \equiv\left\{v_{z}^{e} \in \mathbb{R}^{k} \mid v_{z}^{e}=B \psi+\Gamma^{*} x, \forall x \in \mathbb{R}^{n}\right\}=\left\{v_{z}^{e} \in \mathbb{R}^{k} \mid v_{z}^{e}=B \psi+\left(\Gamma^{q} \Upsilon\right)^{*} x, \forall x \in \mathbb{R}^{n}\right\} \\
& =\left\{v_{z}^{e} \in \mathbb{R}^{k} \mid v_{z}^{e}=B \psi+\Upsilon^{*}\left(\Gamma^{q}\right)^{*} x, \forall x \in \mathbb{R}^{n}\right\}=\left\{v_{z}^{e} \in \mathbb{R}^{k} \mid v_{z}^{e}=B \psi+\Upsilon^{*} x, \forall x \in \mathbb{R}^{q}\right\}
\end{aligned}
$$

In this case, $\Upsilon z$ is not an incentive sufficient aggregate. Indeed, when directly contracting only on $\Upsilon z$, the space of attainable effective incentive rates is the $q$-dimensional linear subspace spanned by the rows of $\Upsilon=\left[I^{q}, \Omega\right]$ and differs from the affine space described above.

Replacing $z$ with any other contractible aggregate $\Upsilon^{\prime} z$ is equivalent to having effective incentives on $z$ in the linear subspace spanned by the rows of $\Upsilon^{\prime}$, which can never equal the affine space $\mathcal{V}_{z}^{e}$ characterized above. Thus, there can be no incentive sufficient aggregate of $z$. In other words, career concerns and surplus sharing have real effects in this setting because the principal cannot neutralize the impact of the implicit incentives.

PROOF OF LEMMA 2. The binding participation constraint (11) gives the fixed wage

$$
f_{2}=-v_{2} \cdot \mathrm{E}_{1}\left[y_{2} \mid \hat{a}_{1}, \hat{a}_{2}\right]+B \mathrm{E}_{1}\left[\theta \mid a_{1}\right]+\kappa\left(\hat{a}_{2}\right)+\frac{1}{2} r \operatorname{var}_{1}\left(w_{2}\right)
$$

\footnotetext{
${ }^{20}$ Saying that the aggregate $\Upsilon z$ of the non-controllable signals $z$ is effectively contractible is not the same as saying that the first $q$ non-contractible signals, corresponding to the first linearly independent columns of $\Gamma$, are effectively contractible. Instead, the $q$-dimensional linear subspace $\mathcal{V}_{z}^{e}$ of $\mathbb{R}^{k}$ may be "tilted" relative to $\mathbb{R}^{q}$, because the aggregation matrix $\Upsilon=\left[I^{q}, \Omega\right]$ aggregates all the $k>q$ non-contractible signals using both the identity matrix, $I^{q}$, for the first $q$ non-contractible signals, $z^{q}$, and redundancy matrix, $\Omega$, for the last $k-q$ non-contractible signals, $z^{k-q}$, i.e., $\Upsilon z=I^{q} z^{q}+\Omega z^{k-q}$.
} 
Substituting in the conditional expectations (1) and gathering the terms that depend on $y_{1}$ we have

$$
f_{2}=-v_{2} \cdot \alpha_{1}+B \alpha_{2}+\kappa\left(\hat{a}_{2}\right)+\frac{1}{2} r \operatorname{var}_{1}\left(w_{2}\right)+\left(B \phi-\Lambda^{*} v_{2}\right) \cdot y_{1}+\left(B \psi-\Gamma^{*} v_{2}\right) \cdot z
$$

Substituting in the agent's total compensation for the two periods yields (14).

We next determine the agent's optimal choice of effort $a_{t}=\left(a_{t 1}, a_{t 2}, \ldots, a_{t m}\right)$ in response to the effective incentives determined above. Since productive effort is not observable and not directly contractible, the agent's action choice maximizes his certainty equivalent of compensation, which in this case is equivalent to $a_{t}$ satisfying the first-order condition

$$
\nabla_{a_{t}} \mathrm{CE}_{t}\left(w_{1}+w_{2} \mid a\right)=\nabla_{a_{t}} \mathrm{E}_{t}\left[w_{1}+w_{2} \mid a\right]-\nabla_{a_{t}} \kappa(a)=0
$$

where $\nabla_{a_{t}}$ denotes the gradient vector of partial derivatives $\left(\partial / \partial a_{t 1}, \partial / \partial a_{t 2}, \ldots, \partial / \partial a_{t m}\right)$. In writing the agent's incentive compatibility constraint, we have used the fact that the action does not affect the variance of compensation. From (19) it follows that the actions induced by the sequence of short-term contracts that satisfy the interim participation constraint (11) and have given explicit incentive rates $v_{1}, v_{2}$ are those in (15).

rROOF OF PROPOSITION 2. Let $a_{1}, a_{2}$ be two implementable actions under short-term contracts subject to the interim participation constraint (11). Let $v_{1}, v_{2}$ denote the associated explicit incentives in the two short-term contracts. The effective incentive on $y_{2}$ is then also $v_{2}$. It follows that a long-term contract subject to renegotiation will induce the same action $a_{2}$ with the same effective incentive $v_{2}$ as long as $v_{2}=v_{R 2}$. Obviously, the converse is true because $v_{2}=v_{R 2}$ will induce the same $a_{2}$ with short-term contracts as with a long-term contract subject to renegotiation where the second-period incentive rate is $v_{R 2}$.

Consider now the effective incentive for the first-period action under short-term contracts, $v_{1}+$ $B \phi-\Lambda^{*} v_{2}$, and assume that the second-period incentive in the renegotiation offer under long-term contracting is as determined before, $v_{2}=v_{R 2}$. Substituting $v_{2}=v_{R 2}$ into the effective incentive for the first-period action under long-term contracts gives $v_{I 1}+B \phi+\Lambda^{*}\left(v_{I 2}-v_{R 2}\right)$. Setting $v_{I 2}=0$ 
and $v_{I 1}=v_{1}$ will give the same effective incentive on $y_{1}$ and the same induced action $a_{1}$ with a long-term contract subject to the renegotiation constraint (3). To prove the converse, one simply works through the effective incentives in reverse order-we leave the details to the reader.

To show that the principal and the agent each get the same payoff under both contract regimes, we note that $\left(a_{1}, a_{2}\right)$ are induced with the same effective incentive rates. Obviously, the agent's effort costs are the same, and the risk premia are also the same since the agent's initial participation constraints are the same in both settings.

\section{References}

Adams, R., B. E. Hermalin, and M. S. Weisbach. 2010. The role of boards of directors in corporate governance: A conceptual framework and survey. Journal of Economic Literature 48(1), 58-107.

Aghion, P., M. Dewatripont, and P. Rey. 1994. Renegotiation design with unverifiable information. Econometrica 62(2), 257-282.

American Accounting Association's Financial Accounting Standards Committee. 2007. The FASB's conceptual framework for financial reporting: A critical analysis. Accounting Horizons 21(2), 229-238.

Antle, R. and J. S. Demski. 1988. The controllability principle in responsibility accounting. The Accounting Review 63(4), 700-718.

Arya, A. and B. Mittendorf. 2005. Offering stock options to gauge managerial talent. Journal of Accounting and Economics 40, 189-210.

Arya, A. and B. Mittendorf. 2011. The benefits of aggregate performance metrics in the presence of career concerns. Management Science 57, 1424-1437.

Autrey, R. L., S. S. Dikolli, and D. P. Newman. 2007. Career concerns and mandated disclosure. Journal of Accounting and Public Policy 26, 527-554. 
Autrey, R. L., S. S. Dikolli, and D. P. Newman. 2010. Performance measure aggregation, career incentives, and explicit incentives. Journal of Management Accounting Research 22, 115131.

Christensen, P. O., J. S. Demski, and H. Frimor. 2002. Accounting policies in agencies with moral hazard and renegotiation. Journal of Accounting Research 40, 1071-1090.

Christensen, P. O., G. A. Feltham, C. Hofmann, and F. Șabac. 2003. Timeliness, accuracy, and relevance in dynamic incentive contracts. Working paper, University of British Columbia.

Christensen, P. O., G. A. Feltham, and F. Șabac. 2003. Dynamic incentives and responsibility accounting: A comment. Journal of Accounting and Economics 35, 423-436.

Christensen, P. O., G. A. Feltham, and F. Șabac. 2005. A contracting perspective on earnings quality. Journal of Accounting and Economics 39, 265-294.

Christensen, P. O., H. Frimor, and F. Șabac. 2013. The stewardship role of analyst forecasts, and discretionary versus non-discretionary accruals. European Accounting Review 22(2), 257-296.

Christensen, P. O., F. Șabac, and J. Tian. 2010. Ranking performance measures in multi-task agencies. The Accounting Review 85(5), 1545-1575.

Demski, J. S. 1998. Performance measure manipulation. Contemporary Accounting Research 15(3), 261-285.

Demski, J. S. and H. Frimor. 1999. Performance measure garbling under renegotiation in multiperiod agencies. Journal of Accounting Research 37, 187-214.

Dewatripont, M., I. Jewitt, and J. Tirole. 1999. The economics of career concerns, part I: Comparing Information Structures. Review of Economic Studies 66, 183-198.

Dutta, S. 2008. Managerial expertise, private information, and pay-performance sensitivity. Management Science 54(3), 429-442. 
Dutta, S. and S. Reichelstein. 1999. Asset valuation and performance measurement in a dynamic agency setting. Review of Accounting Studies 4, 235-258.

Dye, R. A. 1983. Communication and post-decision information. Journal of Accounting Research 21(2), 514-533.

Fama, E. F. 1980. Agency problems and the theory of the firm. Journal of Political Economy 88(2), 288-307.

Feltham, G. A. and J. Xie. 1994. Performance measure congruity and diversity in multi-task principal/agent relations. The Accounting Review 69, 429-453.

Gibbons, R. and K. J. Murphy. 1992. Optimal incentive contracts in the presence of career concerns: Theory and evidence. Journal of Political Economy 100, 468-504.

Gigler, F. B. and T. Hemmer. 2001. Conservatism, optimal disclosure policy, and the timeliness of financial reports. The Accounting Review 76(4), 471-493.

Glover, J. C., Y. Ijiri, C. B. Levine, and P. J. Liang. 2005. Separating facts from forecasts in financial statements. Accounting Horizons 19(4), 267-282.

Hayes, R. M. and S. Schaefer. 2000. Implicit contracts and the explanatory power of top executive compensation for future performance. The RAND Journal of Economics 31(2), 273-293.

Hermalin, B. E. and M. L. Katz. 1991. Moral hazard and verifiability: The effects of renegotiation in agency. Econometrica 59(6), 1735-1753.

Hermalin, B. E. and M. S. Weisbach. 1998. Endogenously chosen boards of directors and their monitoring of the CEO. American Economic Review 88(1), 96-118.

Holmström, B. 1999. Managerial incentive problems: A dynamic perspective. Review of Economic Studies 66, 169-182.

Holmström, B. and P. Milgrom. 1991. Multitask principal-agent analyses: Incentive contracts, asset ownership, and job design. Journal of Law, Economics and Organization 7, 24-52. 
Indjejikian, R., M. Matejka, and J. D. Schloetzer. 2014. Target ratcheting and incentives: Theory, evidence, and new opportunities. The Accounting Review 89(4), 1259-1267.

Indjejikian, R. and D. Nanda. 1999. Dynamic incentives and responsibility accounting. Journal of Accounting and Economics 27, 177-201.

Indjejikian, R. J., M. Matejka, K. A. Merchant, and W. A. V. der Stede. 2014. Earnings targets and annual bonus incentives. The Accounting Review 89(4), 1227-1258.

Kaarbøe, O. M. and T. E. Olsen. 2006. Career concerns, monetary incentives, and job design. Scandinavian Journal of Economics 108(2), 299-316.

Kaarbøe, O. M. and T. E. Olsen. 2008. Distorted performance measures and dynamic incentives. Journal of Economics \& Management Strategy 17(1), 143-183.

MacLeod, W. B. 2003. Optimal contracting with subjective evaluation. The American Economic Review 93(1), 216-240.

Meyer, M. A. and J. Vickers. 1997. Performance comparisons and dynamic incentives. Journal of Political Economy 105(3), 547-581.

Șabac, F. 2007. Dynamic agency with renegotiation and managerial tenure. Management Science 53(5), 849-864.

Șabac, F. 2008. Dynamic incentives and retirement. Journal of Accounting and Economics 46, $172-200$.

Șabac, F. 2015. Ranking performance measures when contracts are renegotiated. Working paper, University of Alberta.

Sabac, F. and J. J. Tian. 2015. On the stewardship value of soft managerial reports. The Accounting Review 90(4), 1683-1706.

Șabac, F. and J. Yoo. 2018. Performance measure aggregation in multi-task agencies. Contemporary Accounting Research 35(2), 716-733. 
Stocken, P. C. 2000. Credibility of voluntary disclosure. The RAND Journal of Economics 31(2), 359-374.

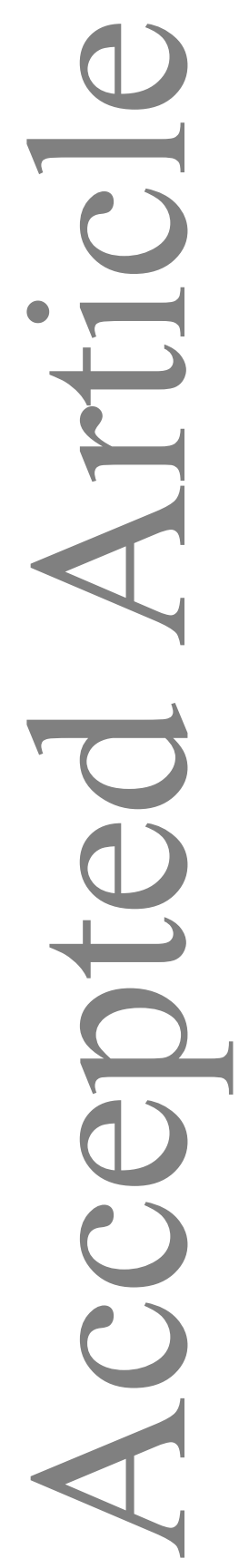





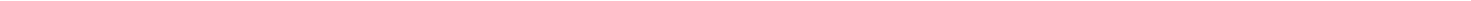

